\title{
YANÁLISE DAS TAXAS \\ DE ABANDONO NOS \\ ANOS FINAIS DO ENSINO \\ FUNDAMENTAL E DO \\ ENSINO MÉDIO A PARTIR \\ DAS CARACTERÍSTICAS DAS \\ ESCOLAS
}

\author{
Robson dos Santos ${ }^{I}$ \\ Ana Elizabeth M. Albuquerque ${ }^{\text {II }}$
}

http://dx.doi.org/10.24109/9786581041076.ceppe.v2a2

\section{RESUMO}

O abandono escolar constitui um tipo de ruptura com a escolarização obrigatória e pode acarretar efeitos na trajetória educacional dos indivíduos e na universalização da educação básica, como é objetivado pelas metas 2 e 3 do Plano Nacional de Educação (PNE); e para os sistemas de ensino, que acabam por ter que responder às demandas por ampliação da escolaridade de jovens e adultos, como perseguem as metas 8, 9 e 10 do referido Plano. Nesse contexto, o estudo analisa, de modo exploratório, se as características internas e de organização dos estabelecimentos e sistemas de ensino

\footnotetext{
Uma versão inicial e parcial deste trabalho foi apresentada no $19^{\circ}$ Congresso Brasileiro de Sociologia (Florianópolis, SC, UFSC, 2019).

I Doutor e mestre em sociologia pela Universidade Estadual de Campinas (Unicamp) e em política social pela Universidade de Brasília (UnB) e graduado em ciências sociais pela Universidade Estadual Paulista (Unesp). Possui especialização em estatística aplicada. Tem experiência como sociólogo em órgãos da Administração Pública Federal como docente de sociologia no ensino médio e na educação superior. Atualmente, trabalha como Pesquisador-Tecnologista em Informações e Avaliações Educacionais no Instituto Nacional de Estudos e Pesquisas Educacionais Anísio Teixeira (Inep). Áreas de interesse e atuação atuais: sociologia da educação, educação de populações do campo, educação de jovens e adultos, indicadores educacionais e métodos quantitativos em ciências sociais.

II Doutora em educação na área de políticas públicas e gestão da educação; mestre em gestão da educação; graduada em ciências sociais, antropologia e em história pela Universidade de Brasília (UnB). Pesquisadora-Tecnologista em Informações e Avaliações do Instituto Nacional de Estudos e Pesquisas Educacionais Anísio Teixeira (Inep). Atua principalmente nos seguintes campos: políticas públicas e gestão da educação; educação profissional e tecnológica (EPT).
} 
se correlacionam às variações nas taxas de abandono por escola nos anos finais do ensino fundamental e do ensino médio. Para fins descritivos, recorre aos indicadores produzidos pelo Instituto Nacional de Estudos e Pesquisas Educacionais Anísio Teixeira (Inep) para os anos de 2014 e 2017. Utilizando dados de 2017, o estudo conduz análises de correlação e regressão para compreender as dimensões relacionadas ao abandono. Os resultados parciais sugerem que, no caso dos anos finais do fundamental, do ponto de vista interno, maior percentual de docentes com nível superior se correlacionam a menores taxas de abandono; em relação ao ensino médio, por sua vez, a ampliação da regularidade do corpo docente e da média de horas-aula por turma se correlacionam a uma redução das taxas de abandono. Além disso, escolas com maior complexidade da gestão apresentaram coeficientes positivos, mesmo com controle por localização e nível socioeconômico.

Palavras-chave: abandono escolar; ensino fundamental; ensino médio; Plano Nacional de Educação.

\section{INTRODUÇÃO}

A Emenda Constitucional n ${ }^{\circ}$ 59, de 2009 (CF, art. 208, inc. I), consagrou no ordenamento jurídico nacional que a "educação básica [é] obrigatória e gratuita dos 4 (quatro) aos 17 (dezessete) anos de idade, assegurada inclusive sua oferta gratuita para todos os que a ela não tiveram acesso na idade própria” (Brasil, 2009). Assim, a expectativa é que os indivíduos que ingressam na pré-escola aos 4 anos de idade concluam a educação básica em uma trajetória regular, com níveis adequados de aprendizagem, idealmente, até os 17 anos. Esse processo, todavia, não contempla a totalidade dos sujeitos no Brasil, visto que um percentual significativo de jovens vivencia formas de ruptura - expressas nas taxas de abandono e de evasão - e acaba deixando, transitória ou definitivamente, o sistema de ensino ao longo do percurso, aprofundando as diferenças entre os grupos sociais (Simões, 2016).

Desse modo, a universalização da educação básica e a ampliação da escolaridade de jovens e adultos ainda se colocam como desafios importantes à melhoria da qualidade educacional no País. A relevância da questão está expressa nos objetivos do Plano Nacional de Educação (PNE 2014-2024), que possui metas dedicadas a garantir a melhoria da cobertura escolar e da conclusão (metas 2 e 3) e a ampliação da escolaridade de jovens a adultos (metas 8, 9 e 10).

Como é registrado pela literatura educacional (Hunt, 2008), as desigualdades socioeconômicas, as disparidades nas condições de acesso e permanência, a qualidade da educação que é oferecida, as vulnerabilidades de várias ordens, entre 
outros fatores, concorrem para (re)produzir fenômenos como o abandono escolar. De tal modo, um número elevado de jovens em situação de distorção idade-série ou já fora da escola sem a educação básica completa e com baixa qualificação acaba por gerar uma demanda por educação de jovens e adultos (EJA), com custos adicionais ao setor público, bem como novos desafios pedagógicos à permanência e à conclusão da educação básica de forma universal.

Os fatores relativos ao contexto socioeconômico remetem às condições estruturais da sociedade brasileira, nas quais os indivíduos e os grupos sociais vivenciam formas assimétricas de acesso aos recursos escolares. Tais aspectos geram fenômenos para os quais as "soluções", muitas vezes, se encontram fora da capacidade de atuação direta dos docentes, dos gestores das unidades escolares ou dos sistemas de ensino (municipais ou estaduais), dado que demandariam, entre outras ações, políticas públicas intersetoriais, que vão além daquelas sob responsabilidade direta dos setores educacionais.

A importância das dimensões socioeconômicas, todavia, não esgota os fatores explicativos do abandono. É preciso considerar também se as características internas e de organização da escola apresentam associação/relação com o abandono escolar, podendo contribuir para a manutenção, a ampliação ou a redução do fenômeno. Por isso, uma análise de indicadores relativos aos processos que se desenvolvem nos estabelecimentos escolares, em muitos casos sob gerência de atores como os docentes e o corpo dirigente das instituições ou dos sistemas de ensino, pode contribuir para uma reflexão conceitual e também para uma compreensão mais detalhada sobre o fenômeno do abandono, assim como das práticas e recursos que, no nível da escola, poderiam colaborar com a sua redução.

O presente estudo analisa as taxas de abandono dos anos finais do ensino fundamental e do ensino médio, em função das características dos estabelecimentos educacionais e dos processos a eles circunscritos, como número de matrículas por escola; número de etapas; média de alunos por turma; média de horas-aula diárias; percentual de docentes com nível superior; índice de regularidade docente; índice de complexidade da gestão escolar; indicador de nível socioeconômico das escolas; distorção idade-série; e taxas de reprovação. É preciso frisar que a análise se concentrou nos indicadores disponíveis no Censo Escolar da Educação Básica, especificamente nas taxas de abandono calculadas por escola, conforme conceito adotado pela Diretoria de Estudos Educacionais do Instituto Nacional de Estudos e Pesquisas Educacionais Anísio Teixeira (Deed/Inep), ${ }^{1}$ e recorreu ao Indicador de Nível Socioeconômico da Escola, para fins de controle da análise.

O estudo teve um caráter exploratório e utilizou como métodos investigativos análises descritivas e de regressão linear múltipla (Hair, 2009), de modo a compreender

1 Ver: Taxas de rendimento escolar (Brasil. Inep, [2018]). 
a distribuição dos dados e verificar as correlações entre as variáveis explicativas e as oscilações nas taxas de abandono por escola. A finalidade não foi constituir um modelo preditivo, mas compreender possíveis associações de características inerentes à escola ("fatores intraescolares"), como o abandono escolar, de modo a trazer subsídios ao monitoramento das metas do PNE dedicadas à universalização da educação básica e à compreensão conceitual do fenômeno.

Nas análises descritivas, foram feitas comparações de dois cortes transversais (Wooldridge, 2016): os anos de 2014 e de 2017, que abarcam, respectivamente, o ano de aprovação do PNE e aquele com as bases de dados mais recentes disponíveis na data de conclusão do estudo. Em relação às análises de correlação e de regressão, o estudo utilizou apenas os dados relativos a 2017, aos quais também foi adicionada a variável de nível socioeconômico das escolas, utilizando os valores relativos a 2015 , de modo a ter um controle para a interpretação dos resultados.

Além desta introdução, o texto realiza uma breve revisão de literatura sobre o abandono escolar; apresenta as bases de dados utilizadas em cada etapa e o tratamento realizado; faz a análise descritiva dos indicadores relativos às taxas de abandono; analisa os resultados dos modelos de regressão; e, por fim, contempla uma síntese das principais conclusões e o delineamento de passos seguintes para a continuidade da pesquisa.

\section{OS SENTIDOS DO ABANDONO ESCOLAR}

A ruptura com o processo de escolarização, de modo que o indivíduo deixe de frequentar a escola nas etapas obrigatórias, seja por um período curto, prolongado ou definitivo, constitui um fenômeno com impactos na trajetória escolar e na qualidade da educação básica, podendo gerar a necessidade de oferta posterior de escolarização para jovens e adultos que, por ventura, tenham evadido e retornem aos sistemas de ensino. Por isso, a ruptura acarreta obstáculos para a efetividade do direito à educação.

No Brasil, o direito à educação está definido nos seguintes marcos legislativos:

\section{QUADRO 1}

\section{PRINCIPAIS MARCOS LEGISLATIVOS DO DIREITO À EDUCAÇÃO BÁSICA OBRIGATÓRIA - BRASIL}

\begin{tabular}{|c|c|c|}
\hline Educação básica e etapas & Idade & Legislação \\
\hline $\begin{array}{l}\text { Educação básica obrigatória e gra- } \\
\text { tuita dos } 4 \text { aos } 17 \text { anos de idade }\end{array}$ & $4-17$ & $\begin{array}{l}\text { - Art. } 208 \text { da Constituição da República } \\
\text { Federativa do Brasil de } 1988 . \\
\text { - Emenda Constitucional n } 59 / 2009 . \\
\text { - Lei no } 9.394 / 1996 \text {, art. } 4^{\circ} \text {, inc. I. } \\
\text { - Lei no } 12.796 / 2013 . \\
\text { - Lei no } 8.069 / 1990, \text { art. } 4^{\circ} .\end{array}$ \\
\hline
\end{tabular}




\section{QUADRO 1}

\section{PRINCIPAIS MARCOS LEGISLATIVOS DO DIREITO À EDUCAÇÃO BÁSICA OBRIGATÓRIA - BRASIL}

\begin{tabular}{|l|c|c|}
\multicolumn{1}{|c|}{ Educação básica e etapas } & Idade & \multicolumn{1}{c|}{ Legislação } \\
\hline $\begin{array}{l}\text { Educação infantil ofertada em cre- } \\
\text { ches para crianças de até } 3 \text { anos de } \\
\text { idade e pré-escolas para crianças de } \\
4 \text { e 5 anos de idade }\end{array}$ & $0-5$ & - Lei no 9.394/1996, art. 30, incs. I e II. \\
$\begin{array}{l}\text { Ensino fundamental obrigatório, } \\
\text { com duração de 9 anos, gratuito na } \\
\text { escola pública, iniciando-se aos } 6 \\
\text { anos de idade }\end{array}$ & $6-14$ & - Lei no 12.796/2013. \\
\hline $\begin{array}{l}\text { Ensino médio, etapa final da edu- } \\
\text { cação básica, com duração mínima } \\
\text { de 3 anos }\end{array}$ & $15-17$ & - Lei no $11.274 / 2006$. \\
\hline
\end{tabular}

Fonte: Elaboração própria com base em dados de Brasil. Inep (2017a).

A relação entre o ano escolar e a idade do indivíduo no sistema educacional brasileiro constitui uma característica da qualidade do fluxo educacional. A trajetória do aluno entre o $1^{\circ}$ e o $9^{\circ}$ ano do ensino fundamental deve se dar, idealmente, entre os 6 e os 14 anos de idade, se não houver atraso. Já o percurso entre o $1^{\circ}$ e $3^{\circ}$ ano do ensino médio ocorreria, portanto, dos 15 aos 17 anos de idade. Desse modo, a efetivação do direito do cidadão e o dever do Estado com a educação formal dar-se-ia, em um sistema educacional eficiente, mediante a garantia de igualdade de condições para o acesso e a permanência no sistema e uma trajetória escolar regular na educação básica obrigatória, gratuita e de qualidade, com ingresso aos 4 anos e conclusão aos 17 anos de idade.

Considerando a trajetória escolar na educação básica, é importante distinguir o "abandono escolar" da "evasão escolar". O primeiro é relativo às taxas de rendimento dentro de um ano letivo, o segundo, ao fluxo/transição entre os anos. Desse modo, em uma situação de abandono, os indivíduos iniciam o ano frequentando a escola e, no decorrer do mesmo ano, deixam de frequentá-la após uma data de referência. Como registra o Inep, o abandono é definido como "a porcentagem de alunos que deixaram de frequentar a escola após a data de referência do Censo" (Brasil. Inep, [2018], p. 2), data essa que era estabelecida ${ }^{2}$ em 30 de maio para o ano de 2017. Nesse caso, os alunos iniciaram o ano letivo, mas não o concluíram. Como explica Klein (2003, p. 110, 112), "um aluno afastado por abandono é qualquer aluno que não foi considerado aprovado ou reprovado. Logo, em um sistema fechado, o número deles é a diferença entre a matrícula inicial e a matrícula final”.

\footnotetext{
2 As informações da matrícula inicial, coletadas na primeira etapa do Censo Escolar, têm como referência a última quarta-feira do mês de maio. (Brasil. MEC, 2007).
} 
Fica caraterizada a evasão escolar, por sua vez, quando um indivíduo que estava matriculado no início do ano $t$ deixa de estar no ano $t+1$. Nesse caso, ele pode ter sido reprovado, abandonado ou mesmo aprovado ao final do ano $t$, e, ao não prosseguir matriculado no ano seguinte, $t+1$, passa a ser considerado em situação de evadido. Essa condição pode materializar, portanto, um tipo de ruptura mais acentuada, dado que o indivíduo não prossegue no sistema de ensino.

Assim, é importante ter em conta as diferenças conceituais para a medição estatística do abandono e da evasão escolar. De um ponto de vista da relação do direito à educação, todavia, ambos expressam rupturas com a trajetória escolar, podendo acarretar prejuízos de aprendizagem e distorção entre idade-série, exigindo ações de correção de fluxo ou um afastamento mais intenso dos vínculos com a instituição escolar.

A literatura sobre abandono escolar, foco deste estudo, é ampla e, muitas vezes, não explicita a distinção com a evasão. Grosso modo, as análises enfatizam ora o contexto socioeconômico e cultural em que o estudante e a escola se localizam, ora as características de estrutura e os processos no interior dos estabelecimentos de ensino como essenciais para se compreender a questão. Assim, o abandono escolar pode decorrer da "necessidade de ingresso precoce no mercado de trabalho; estranhamento e falta de adaptação ao modelo escolar (principalmente no ensino médio); dificuldade de acesso ao estabelecimento escolar". (Saraiva, 2010). O fenômeno é prevalente entre os mais pobres, indicando a importância do fator renda (Neri, 2009). A questão do abandono é analisada também sob a ótica do engajamento dos jovens no processo educacional (Insper, 2017). Outro conjunto de influências e dimensões também concorrem para o abandono, como o uso de

[...] drogas, tempo na escola, sucessivas reprovações, falta de incentivo da família e da escola, necessidade de trabalhar, excesso de conteúdo escolar, alcoolismo, localização da escola, vandalismo, falta de formação de valores e preparo para o mundo do trabalho, podem ser considerados decisivos no momento de ficar ou sair da escola (Silva Filho; Araújo, 2017, p. 36).

Ainda que o abandono esteja fortemente relacionado à pobreza, outros fatores sociais também o afetam. Acrescente-se, de acordo com revisão de literatura feita por Hunt (2008), problemas de saúde; a situação de órfãos; migrações internas ou externas e as consequentes dificuldades em acessar a educação nas novas áreas em termos de linguagem, discriminação, falta de identificação, documentação etc.; crianças de grupos linguísticos minoritários; gravidez na adolescência; casamento precoce; práticas sociais de gênero nas famílias, comunidades e escolas, entre outras. Para Hunt (2008), a escolaridade dos pais também se relaciona à disposição de frequentar a escola por um período mais longo, particularmente o nível de escolaridade da mãe, que influenciaria o tempo de acesso para as meninas. A percepção da importância que os membros da família atribuem à escolarização, assim como a da qualidade da 
educação escolar recebida e da capacidade de as crianças progredirem por meio do sistema de ensino afetam a prioridade atribuída à escolaridade dentro do lar, podendo repercutir, também, no abandono.

Ao lado disso, Hunt (2008) também revisa estudos que tratam da relevância de componentes associados à estrutura escolar e à qualidade dos processos no interior da escola. De acordo com a autora, fatores como ausência de responsabilização e absenteísmo dos docentes, assim como falta de recursos de infraestrutura como mesas, banheiros, quadro e material de apoio ao trabalho, também são apontados pelos estudos como elementos que contribuem com o abandono. Esses componentes, por sua vez, têm uma relação com as características de contexto da escola e com as características socioeconômicas dos estudantes atendidos, pois, como ressalta a autora,

[...] parece evidente que algumas crianças são mais propensas a receber educação de pior qualidade. Muitas vezes, essas crianças são de famílias mais pobres, às vezes rurais e de grupos socialmente desfavorecidos. Qualidade nesses termos pode estar relacionada a instalações, tempo de ensino, qualidade de ensino etc. ${ }^{3}$ (Hunt, 2008, p. 40, tradução nossa).

Reddy e Sinha (2010), após considerarem a importância do contexto e das características socioeconômicas como associadas ao abandono, com base no caso indiano, também apontam a importância de se considerar a qualidade das condições nas quais a educação é oferecida como elemento importante na compreensão do fenômeno:

Onde a infraestrutura escolar é precária, os professores são mal treinados e motivados e as turmas são numerosas nas escolas do governo, aqueles que não podem pagar a educação privada estarão sempre mais expostos ao risco de exclusão. ${ }^{4}$ (Reddy; Sinha, 2010, p. 16, tradução nossa).

Em uma ampla revisão de estudos sobre school dropout, ${ }^{5}$ autores apontam fatores escolares (school-related factors), tais como o nível de seletividade da escola, o

3 “[...] it seems evident that some children are more likely to receive education of poorer quality. Often these children are from poorer backgrounds, sometimes rural and from socially disadvantaged groups. Quality in these terms might relate to facilities, time on teaching, teaching quality, etc.”

4 "Where school infrastructure is poor, teachers are poorly trained and motivated and classes too large in government schools, those who cannot afford private education will always be more at risk of exclusion".

5 Na literatura em língua inglesa, dropout se refere mais à evasão, enquanto o stopout seria aproximado ao abandono. Todavia, nem sempre a distinção entre elas é suficientemente explícita. Como apontam Stratton; O’Toole; Wetzel (2005, p. 4): "by failing to distinguish between dropouts and stopouts (more permanent versus less permanent withdrawals), researchers may incorrectly identify the factors associated with true dropout behavior. If 'standard' attrition studies have been used to design policy responses to reduce attrition, these policy responses may be inappropriately targeted". 
número de alunos por escola, o tamanho das turmas e da escola, a média de alunos por professor, a ocorrência de atividades extracurriculares e a experiência dos docentes, constituindo-se componentes importantes para se compreender o fenômeno (De Witte et al., 2013). De todo modo, os autores ressaltam a relevância de se considerar, sobretudo, a dinâmica de interação entre os fatores (De Witte et al., 2013).

No Brasil, estudos dedicados a analisar a qualidade educacional, realizados especialmente com base nos resultados das avaliações de larga escala, lidam com fatores intraescolares ou extraescolares (Brooke; Soares, 2008), sobretudo buscando explicar o papel da "[...] unidade escolar sobre o aprendizado de seus alunos" (Andrade; Soares, 2008, p. 388).

De tal modo, o fenômeno do abandono se deve a fatores internos e externos, individuais e coletivos. Trata-se de uma situação multidimensional que exige análises detalhadas de cada um de seus componentes.

\section{BASES DE DADOS E INDICADORES UTILIZADOS}

Os dados utilizados neste estudo se referem aos indicadores educacionais produzidos pelo Inep, com base no Censo Escolar da Educação Básica, divulgados no site do instituto. ${ }^{6}$ Os indicadores são publicados originalmente em agregações: por escolas, municípios, unidades da Federação, regiões e em nível Brasil. Em relação às taxas de abandono, inicialmente foram utilizados os dados agregados em nível nacional para análises descritivas gerais. Na sequência, para as análises de correlação e de regressão, foram trabalhados os indicadores ao nível da escola. Também foram utilizados, para fins de caracterização das condições escolares da população brasileira, os dados da Pesquisa Nacional por Amostra de Domicílios Contínua do Instituto Brasileiro de Geografia e Estatística (PnadC/IBGE) e, para fins de controle das análises, o Indicador de Nível Socioeconômico das Escolas ${ }^{6}$ de 2015, calculado pelo Inep com base nos dados do Sistema de Avaliação da Educação Básica (Saeb).

Foi realizada, inicialmente, a junção entre as bases dos anos de 2014 e 2017, de modo a ter informações, agregadas por escola, sobre o número de matrículas; número de etapas; média de alunos por turma; média de horas-aula diárias; percentual de docentes com nível superior; índice de regularidade docente; índice de complexidade da gestão escolar; indicador de nível socioeconômico das escolas; distorção idadesérie; taxas de reprovação; e taxas de abandono. Em seguida, foram feitas exclusões de casos da base de dados, como se explica adiante.

Nas análises descritivas, o estudo não considerou as escolas que apresentavam taxas de abandono ou de reprovação iguais a 100\%. Também foram retirados os casos que apresentavam média de horas-aula diária por turma superiores a 15h. Ainda em

\footnotetext{
${ }_{6}$ Disponíveis em: < http://portal.inep.gov.br/indicadores-educacionais > .
} 
relação aos casos não utilizados, ficaram de fora as escolas com média de alunos por turma superior a 200 alunos, as que não possuíam informação sobre o percentual de professores com nível superior, bem como as escolas que não tinham dados acerca do abandono.

Desse modo, a análise descritiva final utilizou 62.391 escolas com taxas de abandono dos anos finais do ensino fundamental, no ano de 2014 (após a exclusão de 79 casos), e 61.726 escolas em 2017 (após a exclusão de 60 casos). Em relação ao ensino médio, a base utilizada incluiu 27.311 escolas, em 2014 (após a exclusão de 296), e 27.903 no ano de 2017 (após a exclusão de 505 casos).

Em relação às análises de correlação e regressão, foram incluídos o número de alunos por escolas, a quantidade de etapas e o Indicador de Nível Socioeconômico relativo ao ano de 2015, de forma a ter um controle adicional. Nesse caso, após a junção das bases, restaram, em 2017, 38.212 escolas com oferta de anos finais do ensino fundamental e com dados relativos a todas as variáveis utilizadas. Quanto ao ensino médio, restaram, após os procedimentos indicados e a inclusão de informações sobre o nível socioeconômico, um total de 21.012 escolas com casos válidos para todas as variáveis. Foi sobre esse conjunto específico de instituições que se procederam as investigações apresentadas mais adiante, a partir do Gráfico 8, bem como as análises de correlação e regressão.

Os indicadores escolares selecionados para o estudo foram:

- número de matrículas da escola;

- número de etapas da escola;

- média de alunos por turma;

- média de horas-aula diárias;

- percentual de docentes com nível superior;

- índice de regularidade docente;

- índice de complexidade da gestão escolar;

- indicador de nível socioeconômico das escolas;

- distorção idade-série;

- taxas de reprovação; e

- taxas de abandono.

Desse conjunto, alguns indicadores são autoexplicativos, tais como a média de alunos por turma, o número de matrículas por escola, a média de horas-aula diárias e o percentual de docentes da escola que possuem nível superior. A outros cabem algumas notas explicativas, tais como a distorção idade-série, o Índice de Regularidade Docente (IRD), o Índice de Nível Socioeconômico e o Índice de Complexidade da Gestão Escolar (ICG).

A distorção idade-série constitui um indicador calculado a partir da diferença entre a idade do estudante e o ano/série em que ele está matriculado. Como dito, 
a educação básica obrigatória se estende dos 4 aos 17 anos de idade, dividindo-se em etapas. Assim, entre 4 e 5 anos, a expectativa é que a criança esteja matriculada na pré-escola; entre os 6 e 14 anos, que o estudante frequente e conclua o ensino fundamental; e, por fim, entre 15 e 17 anos, integralize o ensino médio. Ao longo do processo, sempre que um estudante tenha uma idade dois anos superior ao ano/série esperado, configura-se uma situação de distorção idade-série (Brasil. Inep, 2004).

O IRD, por sua vez, avalia a "[...] regularidade do corpo docente nas escolas de educação básica a partir da observação da permanência dos professores nas escolas nos últimos cinco anos [...]” (Brasil. Inep, 2015, p. 1). A elaboração do indicador se justificou em função do reconhecimento de que a alta rotatividade de professores nas escolas pode afetar o estabelecimento de vínculos com a instituição e os alunos, pois um docente que permanece pouco tempo na escola tem menos condições para identificar situações específicas dos estudantes e da comunidade atendida, de dar continuidade a planejamentos ou de contribuir na resolução de eventuais problemas pelos quais a escola possa estar passando. O IRD de 2009 a 2013 retratou uma situação de alta rotatividade dos professores brasileiros (Brasil. Inep, 2015). Assim, o indicador se mostrou adequado ao estudo por possibilitar a verificação da existência de relações entre a regularidade docente e as taxas de abandono escolar.

No IRD, para cada par professor-escola, foi atribuída uma pontuação, de forma que a presença em anos mais recentes e a regularidade em anos consecutivos fossem mais valorizadas. Dessa forma, foi definida uma pontuação por presença, que é maior para anos recentes, e, quando o docente está presente em anos consecutivos, sua pontuação é acrescida de um bônus, chamado de pontuação por regularidade. A presença do docente em uma escola é pontuada de acordo com a Tabela 1. Assim, o indicador é definido como a pontuação final de cada par professor-escola, padronizada para variar de 0 a 5 . Quanto mais próximo de 0 , mais irregular é o professor e, quanto mais próximo de 5 , mais regular.

TABELA 1

PONTUAÇÃO POR PRESENÇA E REGULARIDADE DO DOCENTE NA ESCOLA POR ANO DE ATUAÇÃO

2013

2012

2011

2010

2009
60

30

20

15

12

\section{5}

5

2,5

1,5

Fonte: Brasil. Inep (2015, p. 1).

${ }^{1}$ A pontuação por presença (PP) em cada ano é condicionada à atuação do professor na escola no mesmo ano.

${ }^{2} \mathrm{~A}$ pontuação por regularidade (PR) em cada ano é condicionada à atuação do professor na escola no mesmo ano. 
O ICG é composto por quatro características do estabelecimento de ensino: (1) o porte da escola; (2) o número de turnos de funcionamento; (3) a complexidade das etapas ofertadas pela escola; e (4) o número de etapas/modalidades oferecidas. (Brasil. Inep, 2014). A caracterização de cada um desses componentes leva em conta fatores inerentes aos estabelecimentos.

O porte da escola foi mensurado pelo número de matrículas de escolarização, organizado em seis categorias (até 50 matrículas; de 51 a 150 matrículas; de 151 a 300 matrículas; de 301 a 500 matrículas; de 501 a 1.000 matrículas; e mais de 1.000 matrículas). Assume-se que escolas que atendem mais alunos são mais complexas, dado que demandam maiores recursos físicos e humanos para o trabalho pedagógico, a organização do tempo e a conservação do espaço.

Para o cálculo do número de etapas/modalidades ofertadas pela escola, foram consideradas as seguintes classificações: educação infantil regular; anos iniciais regular; anos finais regular; ensino médio regular; educação profissional regular (incluindo ensino médio integrado); EJA (qualquer etapa); educação especial (qualquer etapa). A variável final se distribui em valores que vão de 1 a 7 , correspondendo ao número de etapas/modalidades oferecidas pela escola. Assume-se que as escolas que oferecem mais etapas são mais complexas, dadas a ampliação do número de estratégias e demandas pedagógicas requeridas pelo tipo de oferta.

A variável etapa-complexidade indica qual das etapas ofertadas pela escola atenderiam, teoricamente, alunos com idade mais elevada. Parte-se do pressuposto de que quanto mais avançada a idade dos alunos e as etapas oferecidas, gerencia-se um número maior de docentes, mais arranjos para a organização das grades curriculares são necessários e mais desafios se configuram para a manutenção do estudante na escola (questões como a distorç ão idade-etapa, conciliação entre trabalho e estudo, questões motivacionais etc.). Para isso, as escolas foram classificadas nas seguintes categorias: escolas com oferta de matrículas até a educação infantil ou anos iniciais do ensino fundamental; até os anos finais do ensino fundamental; até o ensino médio ou a educação profissional; com oferta de EJA (independentemente da etapa).

Para avaliar o número de turnos de funcionamento das escolas, as turmas foram classificadas de acordo com o seu horário de início em: matutino (5h às 10h59); vespertino (11h às 16h59); ou noturno (17h às 4h59) e, por fim, a escola foi classificada de acordo com o número de turnos em que suas turmas funcionam. Assume-se que escolas que funcionam em mais turnos são mais complexas.

As quatros dimensões são, posteriormente, reunidas em uma única medida complexa ordinal, que varia de 0 a 6 . Assim, quanto mais próximo de 0 , menos complexa é a escola e, quanto mais próximo de 6, mais complexa (Tabela 2). 
TABELA 2

\section{DESCRIÇÃO DOS NÍVEIS DE COMPLEXIDADE DE GESTÃO}

\begin{tabular}{|c|l|}
\hline Níveis & \multicolumn{1}{c|}{ Descrição $^{1}$} \\
\hline Nivel 1 & $\begin{array}{l}\text { Porte inferior a 50 matrículas, operando em único turno e etapa e } \\
\text { apresentando a educação infantil ou anos iniciais como etapa mais } \\
\text { elevada }^{2} .\end{array}$ \\
\hline Nivel 2 & $\begin{array}{l}\text { Porte entre } 50 \text { e } 300 \text { matrículas, operando em } 2 \text { turnos, com oferta de } \\
\text { até 2 etapas e apresentando a educação infantil ou anos iniciais como } \\
\text { etapa mais elevada }\end{array}$ \\
\hline Nivel 3 & $\begin{array}{l}\text { Porte entre 50 e 500 matrículas, operando em } 2 \text { turnos, com } 2 \text { ou } 3 \\
\text { etapas e apresentando os anos finais como etapa mais elevada }\end{array}$ \\
\hline
\end{tabular}

\begin{tabular}{|c|c|}
\hline Nivel 4 & $\begin{array}{l}\text { Porte entre } 150 \text { e } 1.000 \text { matrículas, operando em } 2 \text { ou } 3 \text { turnos, com } 2 \\
\text { ou } 3 \text { etapas, apresentando ensino médio/profissional ou a EJA como } \\
\text { etapa mais elevada }{ }^{2} \text {. }\end{array}$ \\
\hline Nivel 5 & $\begin{array}{l}\text { Porte entre } 150 \text { e } 1.000 \text { matrículas, operando em } 3 \text { turnos, com } 2 \text { ou } 3 \\
\text { etapas, apresentando a EJA como etapa mais elevada }{ }^{1} \text {. }\end{array}$ \\
\hline
\end{tabular}

Nivel $6 \quad$ Porte superior a 500 matrículas, operando em 3 turnos, com 4 ou mais etapas, apresentando a EJA como etapa mais elevada ${ }^{2}$.

\footnotetext{
Fonte: Brasil. Inep (2014, p. 6).

${ }^{1}$ Características apresentadas por pelo menos dois terços das escolas.

${ }^{2}$ Considerando a idade dos alunos atendidos.
}

Em conjunto com os indicadores de número de matrículas da escola; número de etapas; média de alunos por turma; média de horas aula-diárias; e percentual de docentes com nível superior, esses indicadores permitiram compor um conjunto de características da gestão da escola que podem trazer subsídios a uma compreensão de como os processos intraescolares que se desenvolvem sob a gerência dos docentes, corpo dirigente das instituições e dos sistemas de ensino podem afetar o abandono escolar.

O Indicador de Nível Socioeconômico das Escolas (Inse) objetiva situar o conjunto dos alunos atendidos por cada escola em um estrato, definido pela posse de bens domésticos, renda e contratação de serviços pela família dos alunos e pelo nível de escolaridade de seus pais. A medida de nível socioeconômico dos alunos foi calculada com os dados socioeconômicos dos questionários contextuais da Avaliação Nacional da Educação Básica (Aneb), da Avaliação Nacional do Rendimento Escolar (Anresc, denominada Prova Brasil) e do Exame Nacional do Ensino Médio (Enem). O nível socioeconômico da escola está definido em seis categorias: "o Grupo 1 congrega as escolas com Inse médio mais baixo e o Grupo 6, com mais alto”. (Brasil. Inep, [2015], p. 10).

Para fins de controle, foram incluídos os dados referentes ao nível socioeconômico da escola, relativo ao ano de 2015. 


\section{ANÁLISES DESCRITIVAS DOS DADOS}

Ao se considerar os níveis de escolaridade alcançados pela população brasileira, nota-se que um percentual elevado daqueles que não frequentavam mais a escola não possuía a educação básica completa. Tratando especificamente dos que tinham 25 anos ou mais, idade na qual o jovem já poderia, em uma trajetória regular, ter concluído inclusive o ensino superior e, portanto, estar fora da escola, é possível observar, com os dados da PnadC de 2012 a 2018 (IBGE), que ao redor de 40\% da referida população não possuía sequer o ensino fundamental completo (Gráfico 1).

Agregando os indivíduos que não frequentavam a escola e que tinham o médio incompleto, o fundamental completo, o fundamental incompleto ou não tinham instrução, os valores eram superiores a $45 \%$ da população de 25 anos ou mais, estando, portanto, fora dos estabelecimentos de ensino sem ter concluído a educação básica. Nesse caso, trata-se de uma parcela da população brasileira que teve acesso à escola, mas que não completou a educação básica, tendo vivenciado, assim, rupturas com o processo escolar. Além disso, também chama a atenção o quantitativo referente aos que não possuíam qualquer nível de instrução, 12,5\% em 2012 e 9,2\% em 2018 (Gráfico 1).

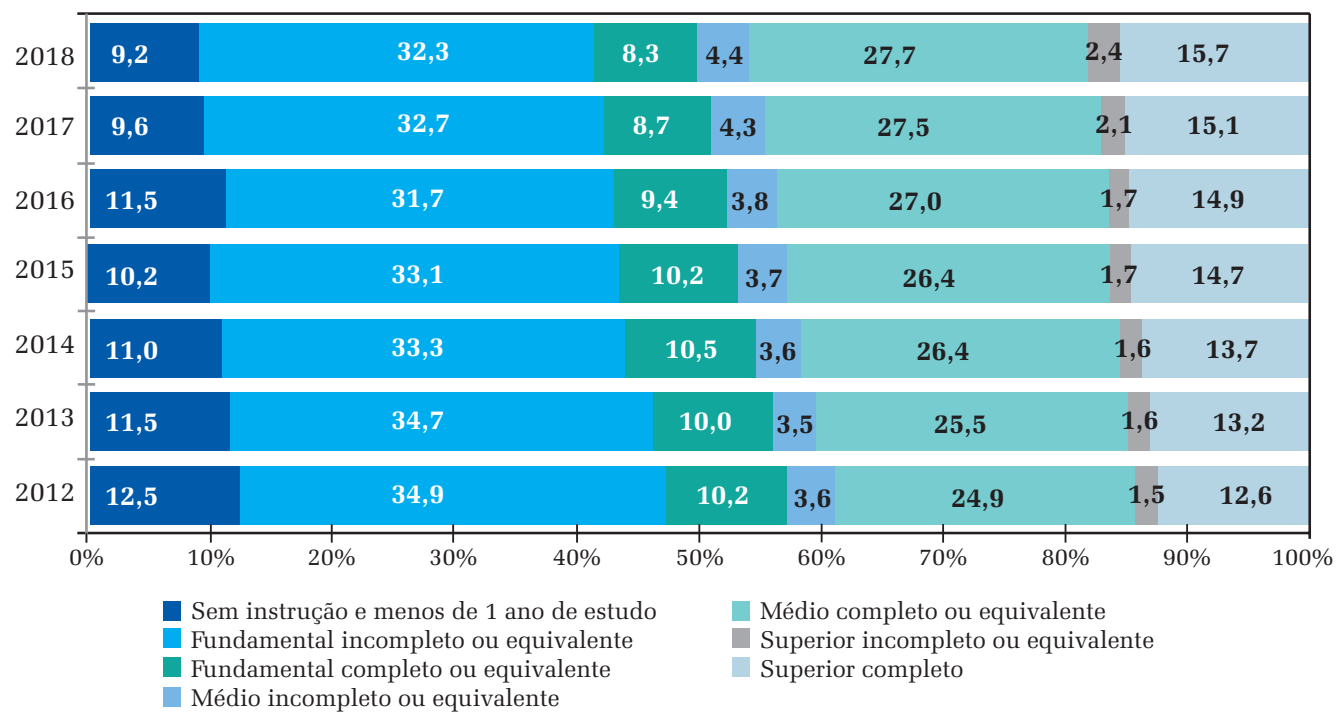

\section{GRÁFICO 1}

\section{POPULAÇÃO DE 25 ANOS OU MAIS QUE NÃO FREQUENTA A ESCOLA, POR NÍVEL DE} ENSINO MAIS ELEVADO QUE CONCLUIU - BRASIL - 2012-2018

Fonte: Elaboração própria com base em dados da Pnad Contínua/IBGE ( $2^{\circ}$ trimestre).

Nos últimos anos, é importante ressaltar que ocorreu, no Brasil, uma redução na taxa de abandono tanto no ensino fundamental como no médio. Em 2007, os anos finais do fundamental apresentavam uma taxa de abandono na faixa de 6,7\%; 
ao longo dos anos, foi sendo reduzida consistentemente, de modo a atingir 2,8\%, em 2017 (Gráfico 2). Desse modo, o percentual daqueles que ingressavam no ensino fundamental e o concluíam sem que ocorresse algum tipo de ruptura com o processo escolar se ampliou, denotando melhoras na eficiência dos sistemas de ensino. Também é relevante destacar que as taxas mais elevadas de abandono se apresentam nos anos finais do ensino fundamental. De todo modo, o fenômeno ainda permanece sendo reproduzido.

Em relação ao ensino médio, é possível verificar que, de modo agregado, as taxas também se reduziram, passando de $13,2 \%$ para $6,1 \%$. Se, por um lado, isso representa um dado positivo, tendo em vista a redução de 7,1 p.p., por outro, revela a permanência de taxas elevadas de abandono no ensino médio, bem maiores, por exemplo, do que as registradas no ensino fundamental (Gráfico 2). Cumpre apontar que os sujeitos na etapa de ensino médio lidam com desafios e complexidades adicionais, como a transição/conciliação trabalho e estudos, as mudanças de escola, a constituição de novos vínculos afetivos e familiares, as reconfigurações da identidade, entre outros fatores com os quais os estabelecimentos de ensino precisam lidar e que podem trazer desafios adicionais à permanência dos estudantes sem que ocorram rupturas com a trajetória escolar.

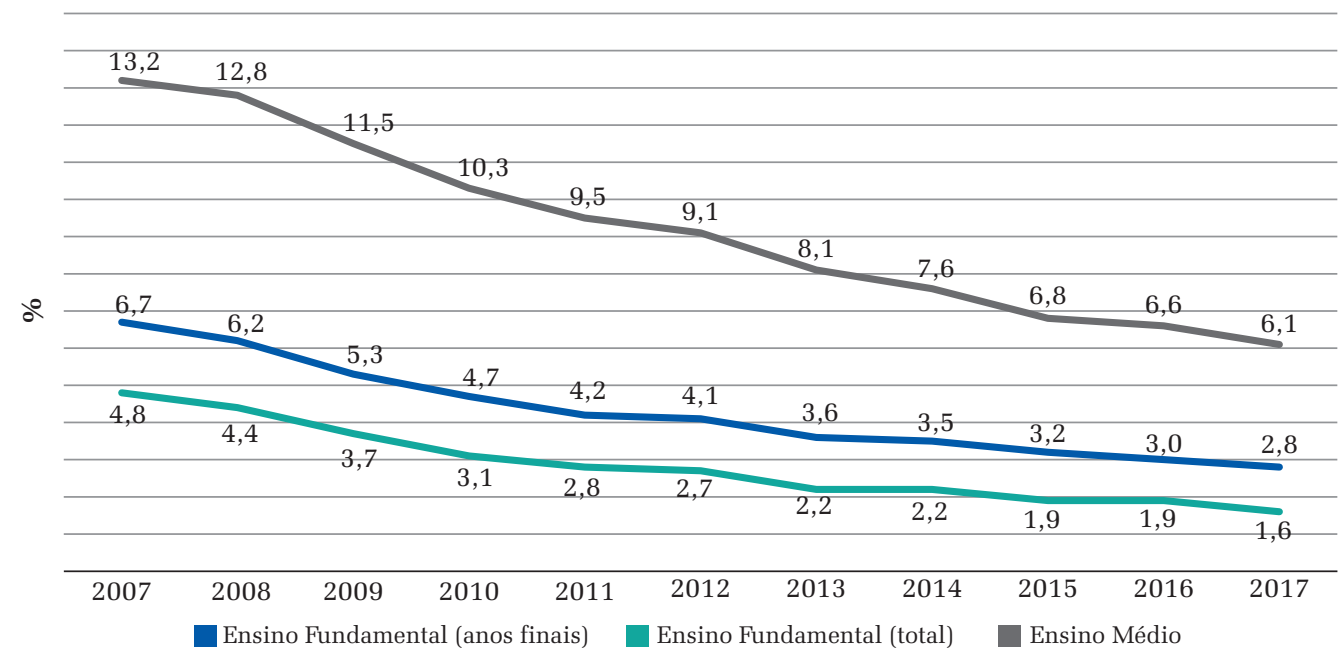

\section{GRÁFICO 2 \\ TAXAS DE ABANDONO POR ETAPAS DE ENSINO - BRASIL - 2007-2017}

Fonte: Elaboração própria com base em dados dos Indicadores Educacionais - Taxas de rendimento/Inep.

O ensino médio apresenta taxas de abandono mais elevadas, levando em conta o nível Brasil (Gráfico 2). Como exemplo, ao conduzir a desagregação, nota-se que é no $1^{\circ}$ ano que o abandono ocorre com maior frequência. Assim como visto em relação ao ensino fundamental, as taxas de abandono passaram por uma redução no período 
analisado (Gráfico 3). Cabe registar que as taxas de reprovação não passaram por diminuição similar, sendo inclusive superiores a 15\% em todo o período considerado quanto ao $1^{\circ}$ ano do ensino médio. Os dados relativos ao $1^{\circ}$ ano do ensino médio parecem sugerir que os estudantes, mesmo reprovados, não abandonam a escola.

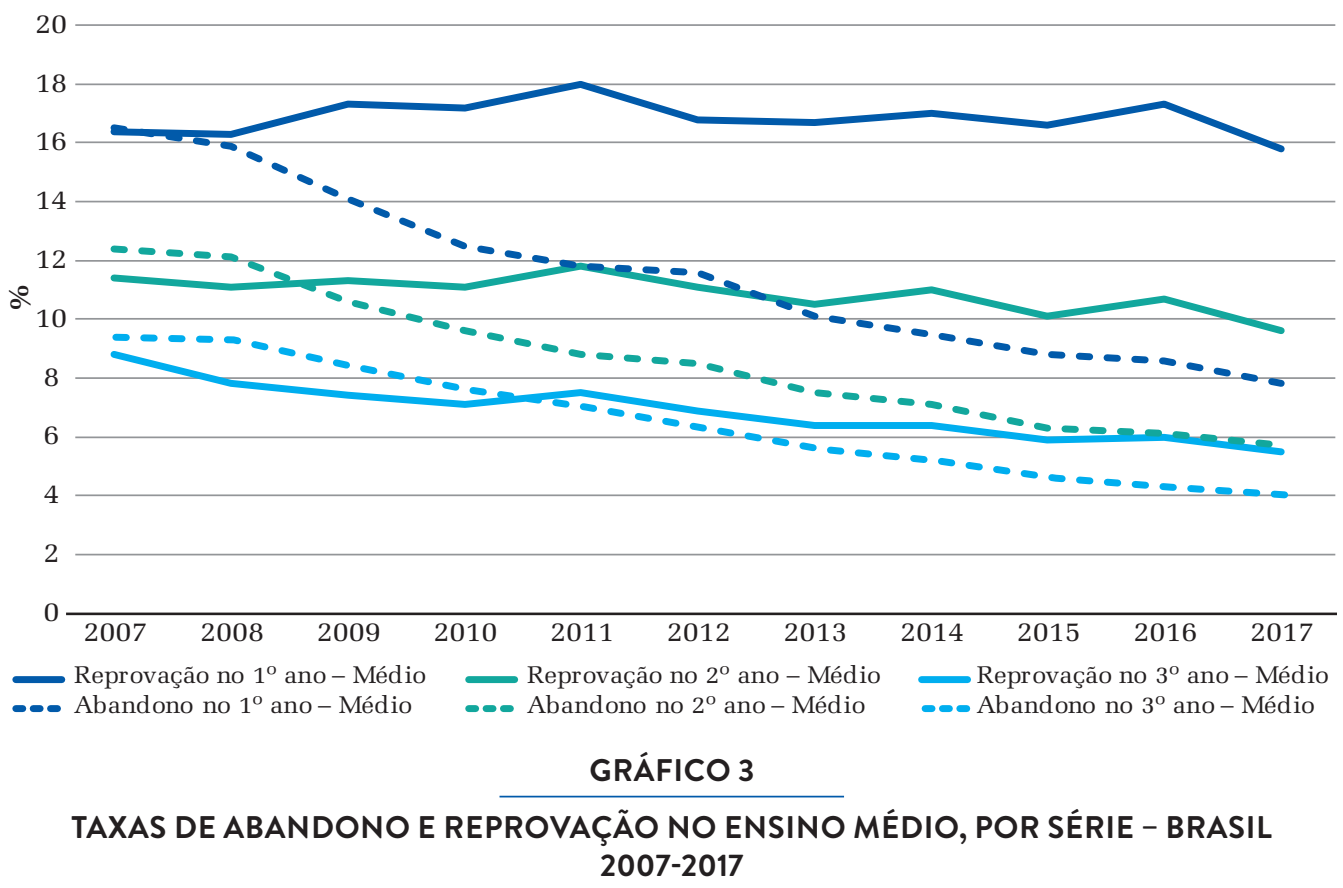

Fonte: Elaboração própria com base em dados dos Indicadores Educacionais - Taxas de rendimento/Inep.

Os dados apresentados nos gráficos 2 e 3 referem-se às médias calculadas para o nível Brasil. Na sequência, são analisadas, de forma descritiva, as informações relativas às médias registradas por escola, a partir das quais os tratamentos antes descritos passam a ser aplicados. As taxas de abandono dos estabelecimentos selecionados para essa etapa do estudo também apresentaram tendência de redução. A comparação dos dados referentes aos anos finais do ensino fundamental, entre 2014 e 2017, sinaliza para um achatamento da distribuição de modo que se aproximou de valores mais próximos a zero (Gráfico 4).

A comparação pela localização da escola demonstra que as posicionadas no campo apresentam maiores percentuais de abandono quando comparadas às urbanas: os valores superiores da distribuição atingiram - descontando os casos extremos percentuais próximos a $20 \%$ nas escolas de anos finais do ensino fundamental situadas no campo (Gráfico 5). 


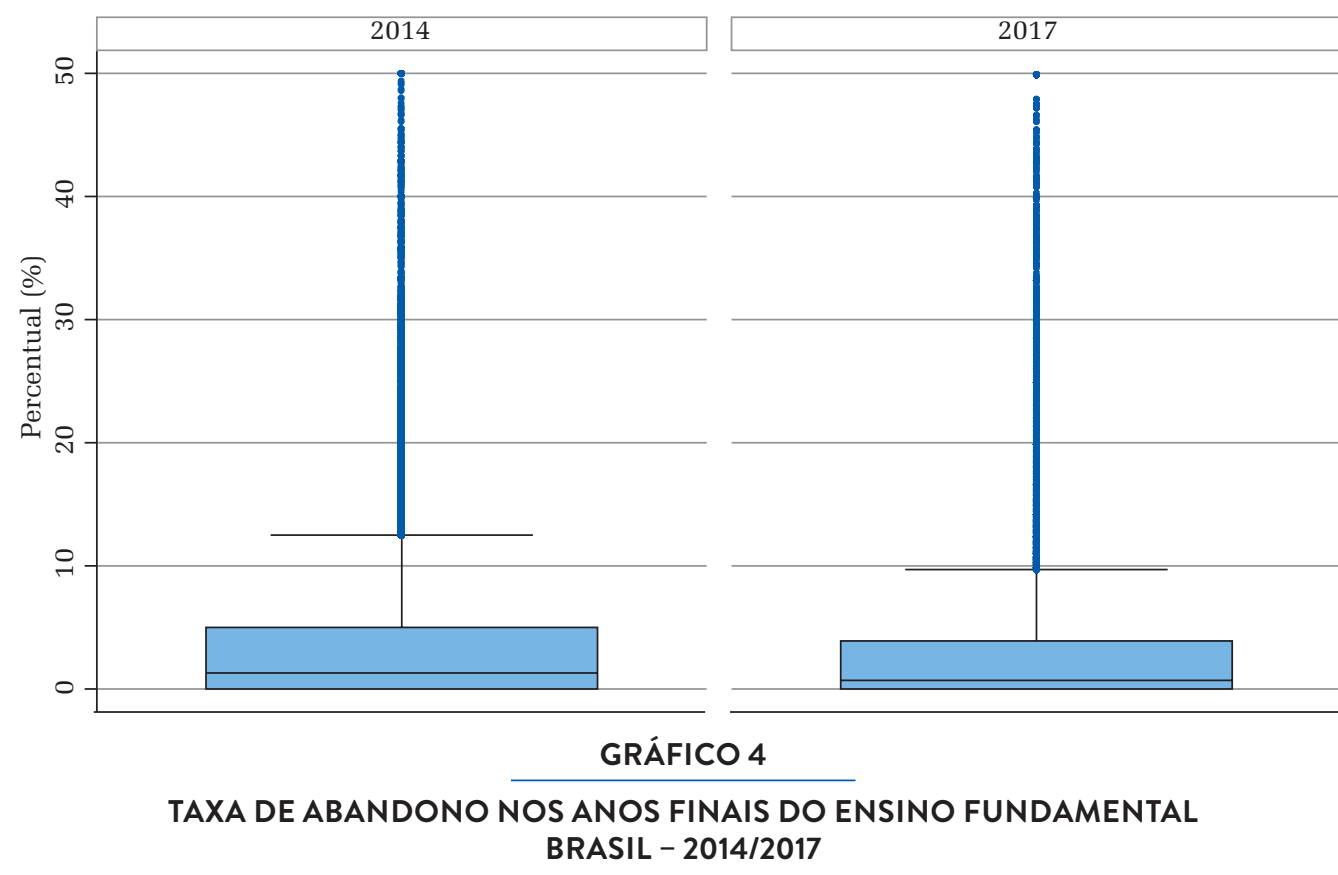

Fonte: Elaboração própria com base em dados dos Indicadores Educacionais - Taxas de rendimento/Inep.
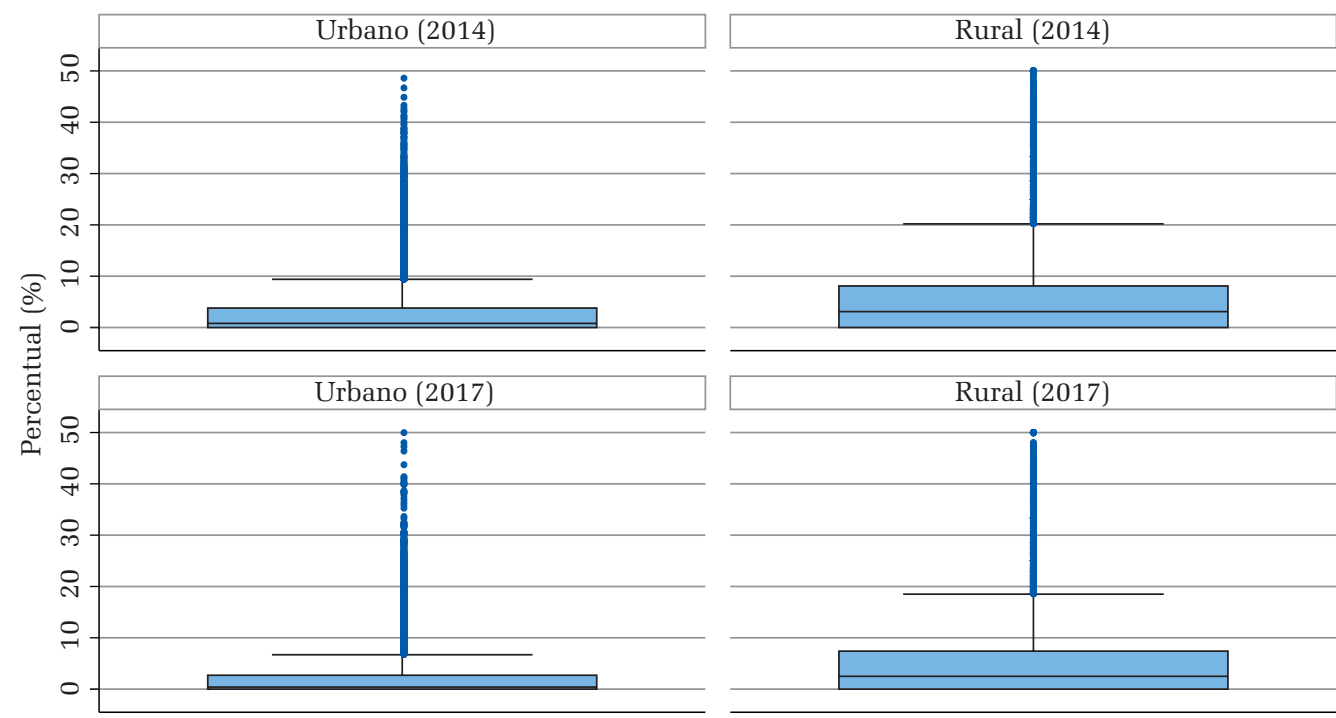

GRÁFICO 5

TAXA DE ABANDONO POR ESCOLAS NOS ANOS FINAIS DO ENSINO FUNDAMENTAL, POR LOCALIZAÇÃO - BRASIL - 2014/2017

Fonte: Elaboração própria com base em dados dos Indicadores Educacionais - Taxas de rendimento/Inep.

A análise descritiva das taxas de abandono referentes às escolas de ensino médio permite verificar que ocorreu uma redução nos valores superiores e na mediana da distribuição, o que segue a tendência já observada na taxa em nível Brasil. Em 2014, 
a taxa de abandono por escola apresentava valores que, na calda superior, rompiam os 20\%. Em 2017, os valores máximos foram reduzidos, mas a quantidade de escolas com taxas de abandono acima de 5\% ainda eram consideráveis (Gráfico 6).

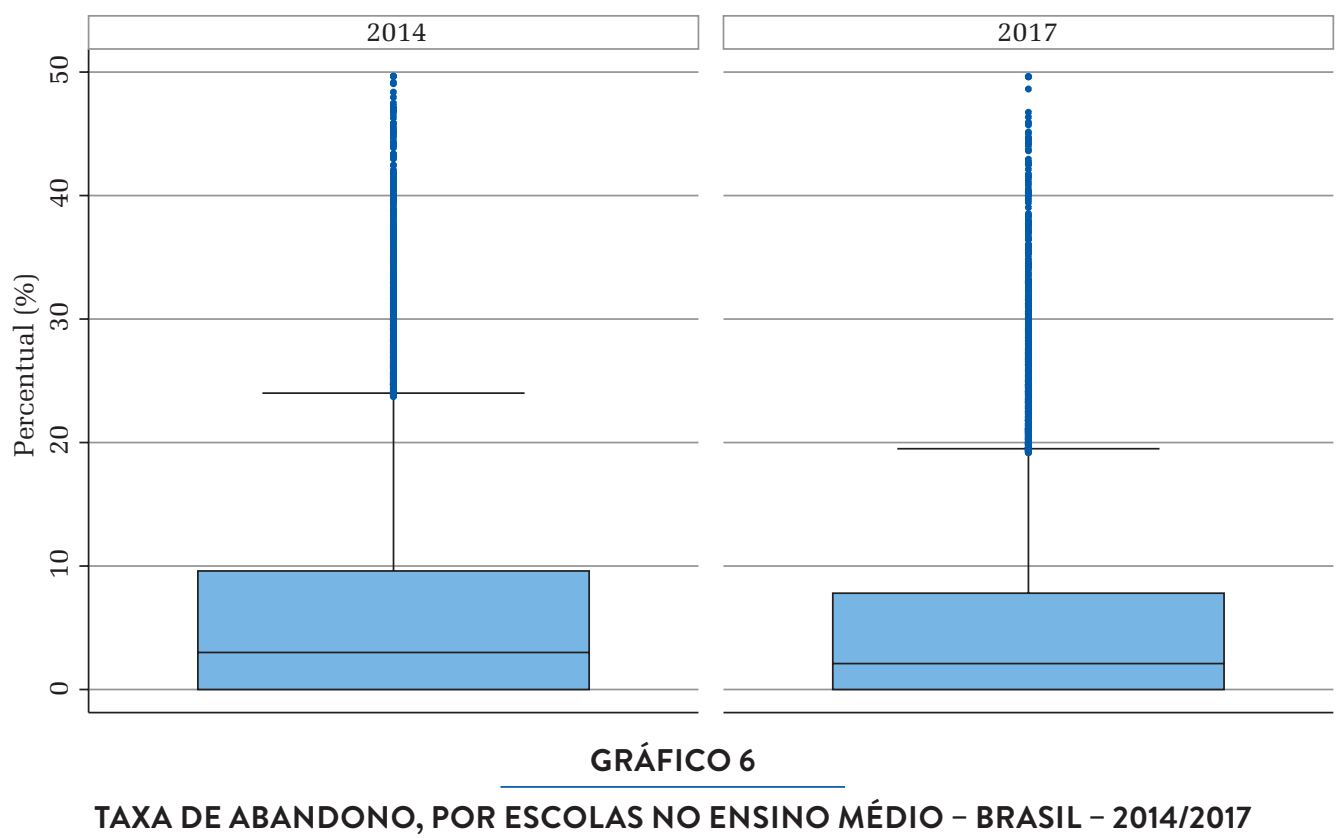

Fonte: Elaboração própria com base em dados dos Indicadores Educacionais - Taxas de rendimento/Inep.

É fato que os valores abarcam realidades heterogêneas, visto que diferentes formas de organização estão inclusas, como as escolas privadas e públicas, federais e estaduais, técnicas ou de ensino propedêutico, entre outras realidades específicas. Já a desagregação por local da escola, que compara a situação entre as posicionadas em espaços urbanos e aquelas em áreas definidas como rurais, permite visualisar algumas diferenças. Em ambos os anos, as taxas médias de abandono no ensino médio das escolas localizadas no campo apresentaram maior frequência de estabelecimentos com taxas de abandono superiores a $20 \%$ e medianas em posições mais elevadas que as observadas para as situadas em áreas urbanas (Gráfico 7).

É necessário frisar que o número de escolas localizadas no campo que oferta o ensino médio é menor que o das urbanas. De todo modo, os valores sugerem uma ocorrência mais frequente de abandono em áreas rurais, o que pode estar associado tanto às condições socioeconômicas como à situação de limitação na infraestrutura dos estabelecimentos do campo, entre outros fatores, conforme aponta a revisão da literatura (Gráfico 7). 


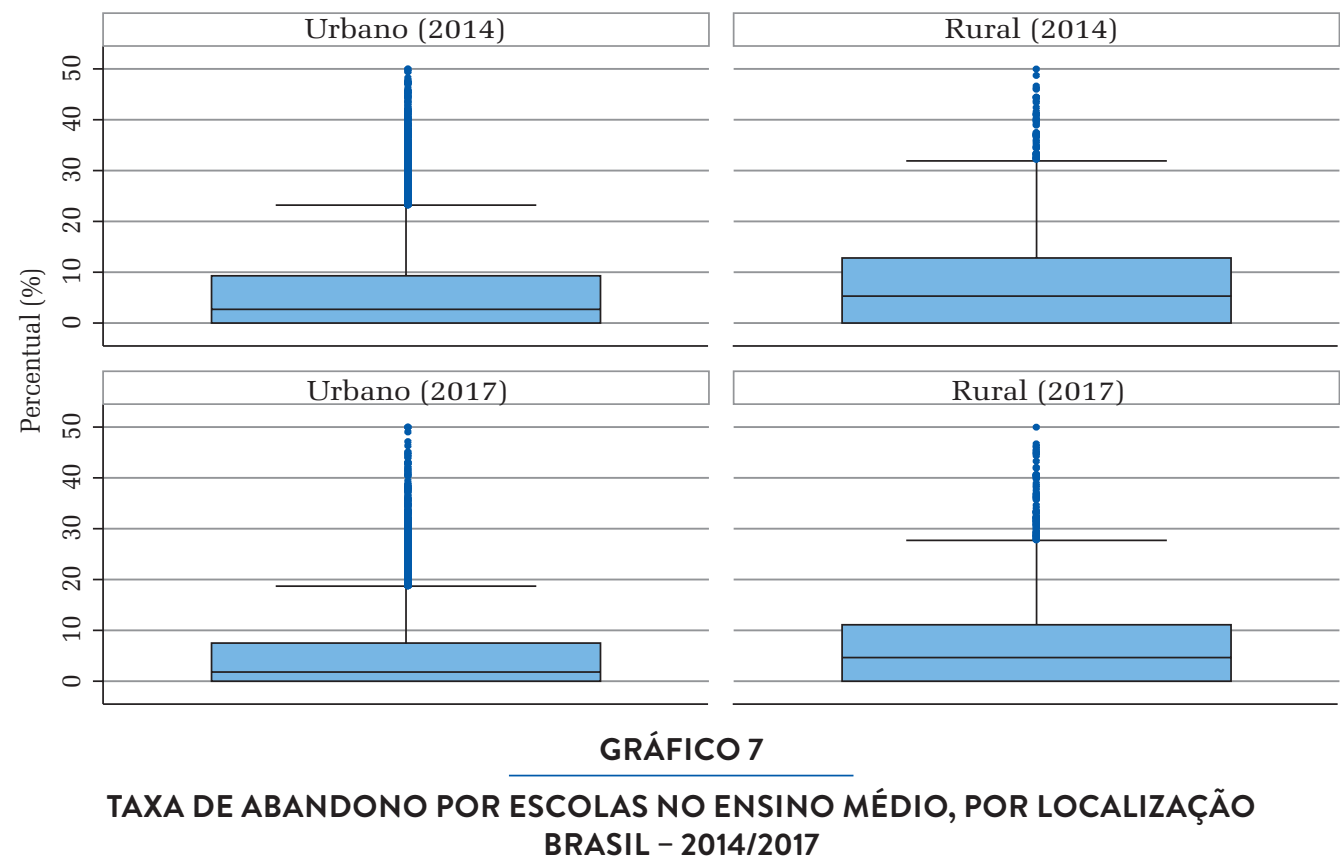

Fonte: Elaboração própria com base em dados dos Indicadores Educacionais - Taxas de rendimento/Inep.

As análises consideram, até aqui, as escolas que possuíam dados para o indicador de abandono. A partir deste ponto, as observações se concentram no ano de 2017 e se referem às que tinham informações para todas as variáveis utilizadas, o que contempla 38.212 escolas dos anos finais do fundamental e 21.012 de ensino médio, como descrito na parte relativa a tratamento dos dados.

A análise das taxas de abandono pelo ICG, no caso do ensino fundamental, não apresentou diferenças muito consistentes na distribuição percentual (Gráfico 8). Em relação ao ensino médio, todavia, as taxas de abandono são mais próximas a zero nas escolas de menor complexidade, enquanto nas escolas de maior complexidade, a distribuição era mais distante de zero (Gráfico 9). É importante lembrar que a oferta do ensino médio também é mais frequente em escolas caracterizadas como de maior complexidade. 


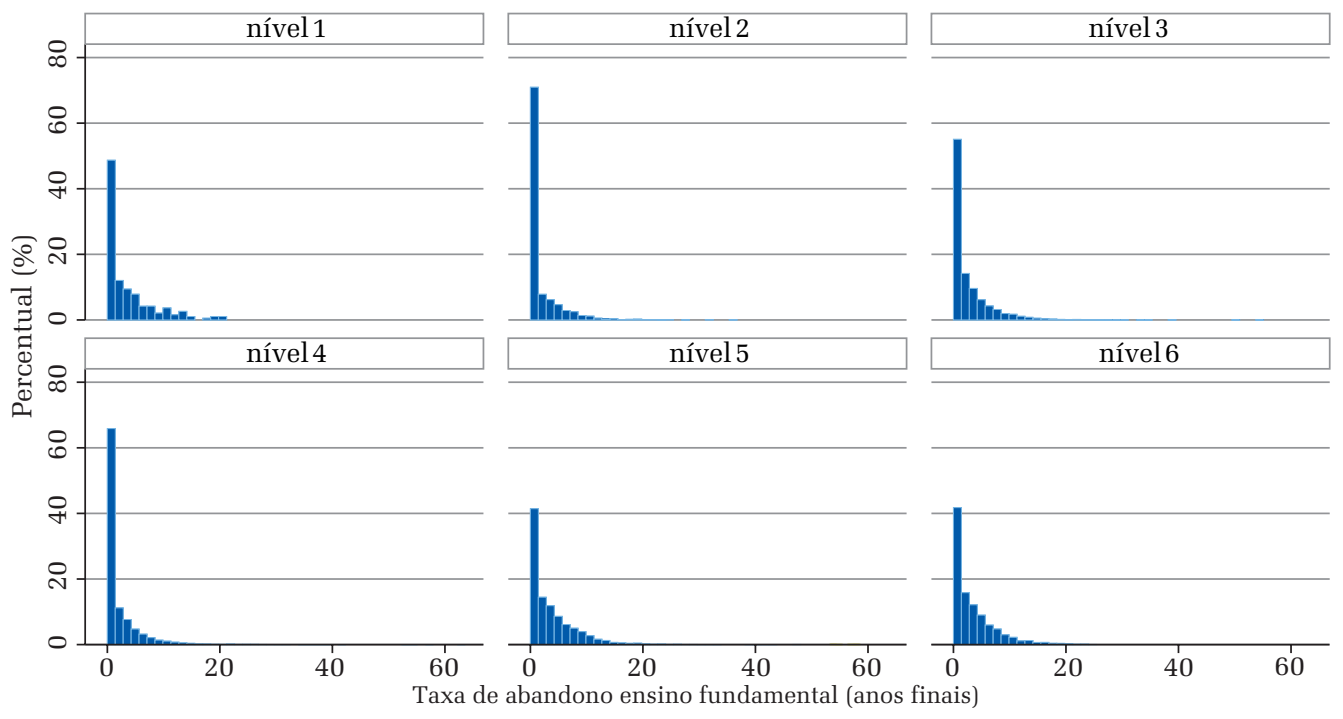

GRÁFICO 8

DISTRIBUIÇÃO PERCENTUAL DA TAXA DE ABANDONO NAS ESCOLAS DOS ANOS FINAIS DO FUNDAMENTAL, POR ÍNDICE DE COMPLEXIDADE DA GESTÃO (ICG) - BRASIL - 2017

Fonte: Elaboração própria com base em dados dos Indicadores Educacionais/Inep.
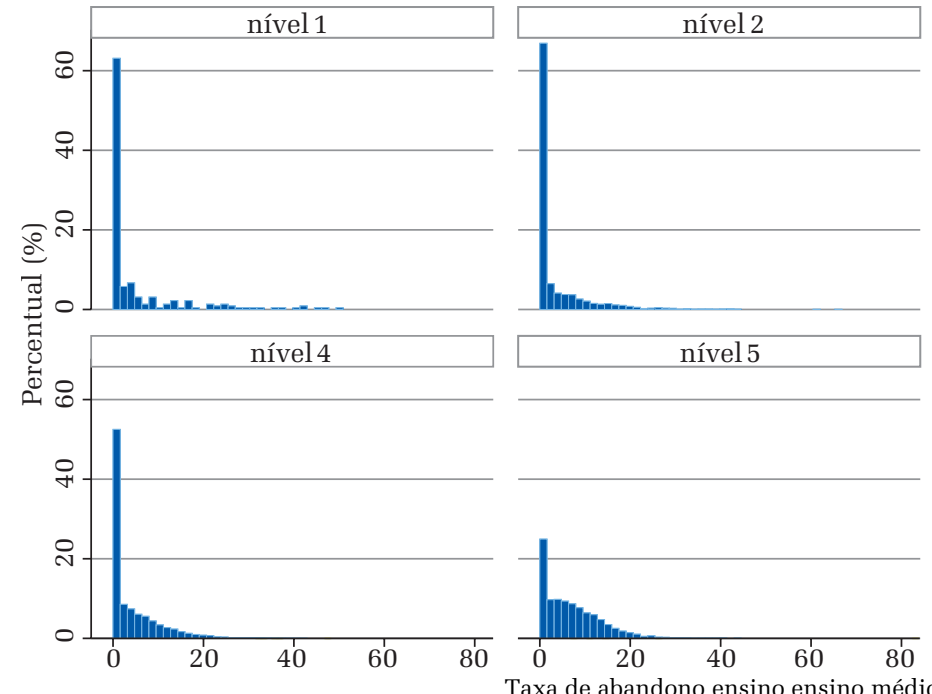

GRÁFICO 9

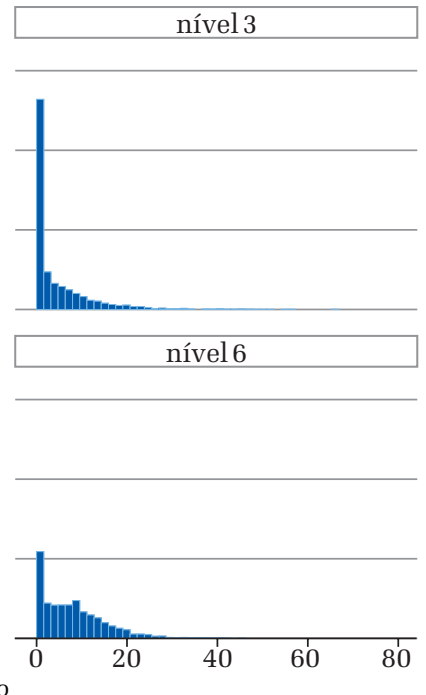

\section{DISTRIBUIĊ̃̃ PERCENTUAL DA TAXA DE ABANDONO NAS ESCOLAS DE ENSINO MÉDIO, POR ÍNDICE DE COMPLEXIDADE DA GESTÃO - BRASIL - 2017}

Fonte: Elaboração própria com base em dados dos Indicadores Educacionais/Inep.

Em relação à variável de controle nível socioeconômico, as taxas de abandono nos anos finais do ensino fundamental iguais ou próximas a zero tendiam a ser mais comuns nos estabelecimentos com maior nível socioeconômico, sobretudo os níveis 
4, 5 e 6 (Gráfico 10). Em relação ao ensino médio, a situação também se verifica, visto que os estabelecimentos com maior nível socioeconômico (nível 5 ou 6) apresentaram, em geral, mais escolas com taxas de abandono próximas a zero (Gráfico 11).
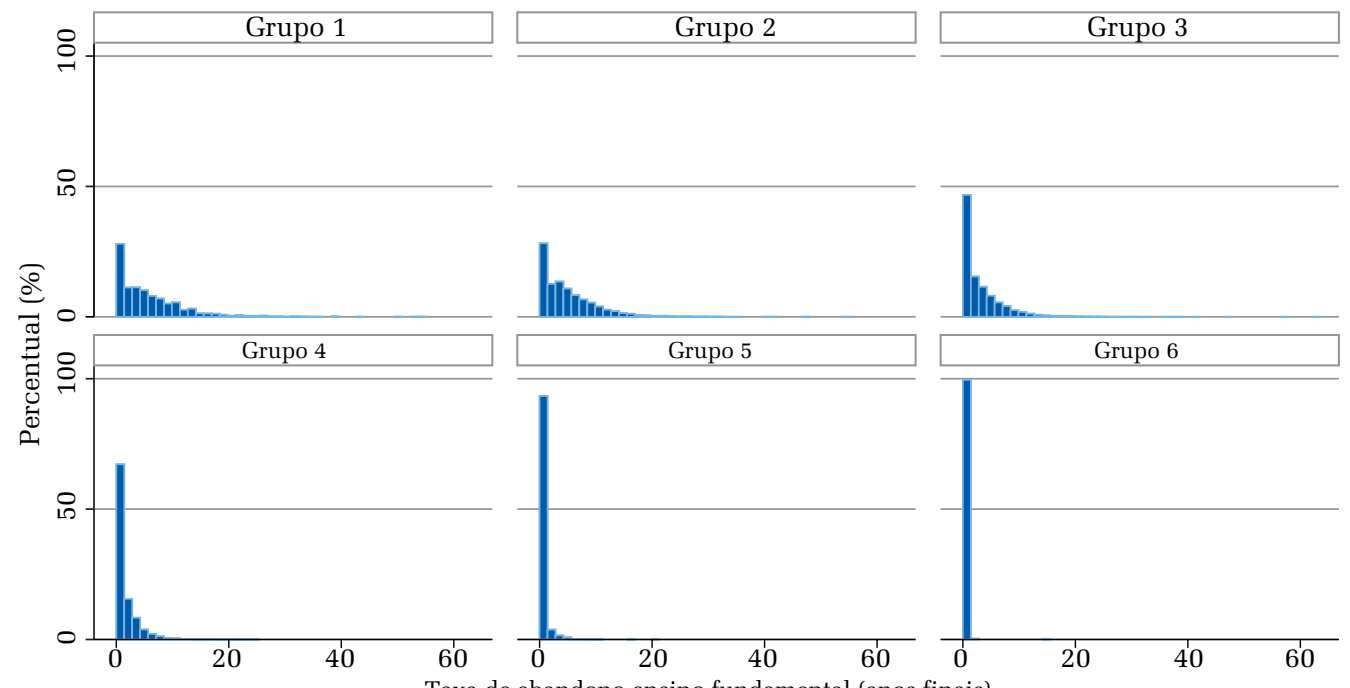

\section{GRÁFICO 10}

\section{DISTRIBUIÇÃO PERCENTUAL DA TAXA DE ABANDONO NAS ESCOLAS DOS ANOS FINAIS DO FUNDAMENTAL, POR NÍVEL SOCIOECONÔMICO - BRASIL - 2017}

Fonte: Elaboração própria com base em dados dos Indicadores Educacionais/Inep (2015).
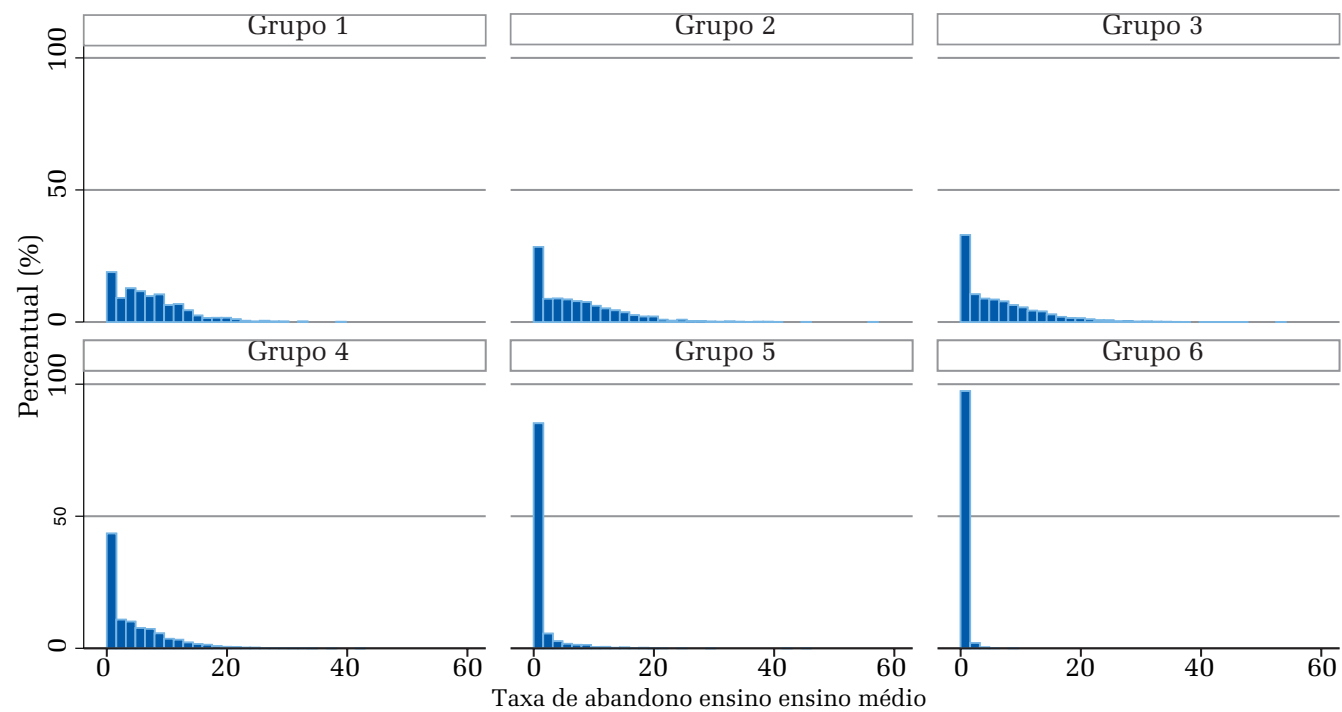

GRÁFICO 11

TAXA DE ABANDONO NAS ESCOLAS DE ENSINO MÉDIO, POR NÍVEL SOCIOECONÔMICO (2015) - BRASIL - 2017

Fonte: Elaboração própria com base em dados dos Indicadores Educacionais/Inep. 
A análise descritiva apontou, no período considerado, uma tendência de redução nas taxas de abandono, tanto nos anos finais do ensino fundamental como no ensino médio, verificada nas taxas agregadas em nível Brasil e nas médias por escola. A desagregação por ICG, que é uma medida composta, indicou que, sobretudo no caso do ensino médio, as escolas com maior complexidade apresentavam distribuição mais elevada das taxas de abandono. No caso do nível socioeconômico, os dados também indicam que as escolas que reuniam alunos com menor nível ostentavam maiores taxas de abandono.

Na sequência, passa-se a investigar a correlação entre as taxas de abandono e as demais características dos estabelecimentos de ensino. Inicialmente, realizou-se uma análise de correlação e, na sequência, modelos de regressão múltipla, visando compreender as relações que podem existir entre as carcterísticas da escola e as taxas de abandono, incluindo o controle por nível socioeconômico.

\section{CARACTERÍSTICAS ESCOLARES E AS TAXAS DE ABANDONO}

Abandonar a escola pode ampliar a distorção idade-série, acarretar prejuízos de aprendizado ao estudante e ser um indício de situações de vulnerabilidade, sobretudo quando se consideram os anos finais do ensino fundamental, etapa na qual as taxas de abandono se elevam. No ensino médio, o abandono pode se associar às necessidades de conciliar escola-trabalho, gravidez na adolescência, entre outras, como visto na literatura antes citada. O que se buscou nessa etapa foi investigar se as taxas de abandono se associam às características e aos processos imanentes à escola. Para isso, foram utilizados apenas os dados relativos aos estabelecimentos que possuíam informações sobre o nível socioeconômico de 2015 e dados válidos em 2017 para todos os indicadores utilizados.

A análise da matriz de correlação entre as variáveis quantitativas dos anos finais do ensino fundamental (Tabela 3) demonstra que as taxas de abandono das escolas apresentavam correlação moderada positiva com a distorção idade-série (r de Pearson de 0,582$)$ e com a reprovação $(0,308)$. Quanto à regularidade docente, a taxa de abandono por escola apresentava uma correlação negativa e muito fraca $(-0,021)$, situação análoga se verifica em relação ao número de alunos por turma, média de horasaula, número de etapas e de matrículas. O percentual de docentes com nível superior na escola apresentava uma correlação negativa de -0,188 com a taxa de abandono. Quanto ao nível socioeconômico, nota-se que a correlação era negativa e moderada $(-0,415)$. Desse modo, entre as características "internas" à escola, foi possível perceber que a distorção e a reprovação apresentavam correlação positiva com o abandono, ao passo que o percentual de docentes com nível superior indicava correlação negativa. 


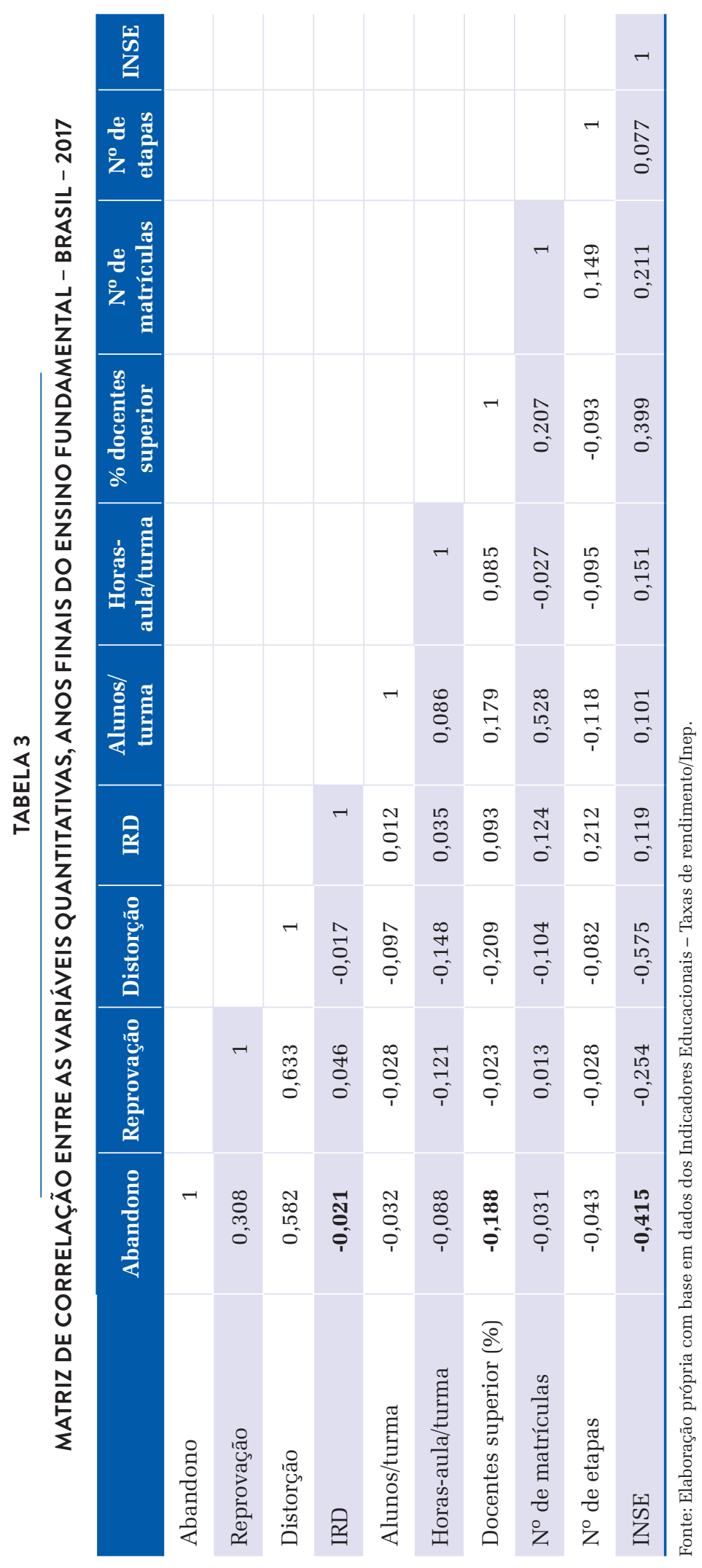


Em relação ao ensino médio, a análise da matriz de correlação apontava que a taxa de abandono apresentava correlação positiva com a reprovação $(0,268)$, com a distorção idade-série $(0,625)$ e com o número de matrículas na escola $(0,101)$. Por outro lado, a média de horas-aula por turma $(-0,311)$ e o índice de regularidade docente $(-0,148)$ apresentaram uma correlação negativa com o abandono, sugerindo que a ampliação nos valores desses indicadores era concomitante à redução do abandono. Considerando os dados utilizados nessa etapa do estudo, cumpre assinalar ainda que o nível socioeconômico registrava, em 2017, uma correlação negativa de -0,355 com a taxa de abandono no ensino médio, isso é, o aumento do nível socioeconômico correlacionava-se a uma redução do abandono escolar (Tabela 4).

Na sequência, foram utilizados modelos de regressão linear multivariada de modo a compreender a associação entre características da escola e o abandono, controlando por variáveis como a localização e o nível socioeconômico do estabelecimento de ensino. Em outras palavras, o pressuposto que se buscou analisar foi se a participação dos componentes circunscritos ao lócus escolar se associa com a taxa de abandono do estabelecimento de ensino, que constitui a variável dependente da análise, enquanto as independentes são as que aparecem no Apêndice A (Tabela A1).

É importante registrar ainda que, nessa etapa, optou-se por trabalhar também com as variáveis que compõem o ICG, em particular o número de matrículas e de etapas. Desse modo, busca-se compreender qual dimensão específica do indicador se associa ao abandono. O ICG foi incluído no modelo transformado em variáveis dicotômicas para verificar a sua participação na explicação da variação total, tendo como categoria de referência as escolas com nível 1 de complexidade da gestão. Optou-se também por não incluir a reprovação nos modelos, em função da relação de endogenia que ela guarda com o indicador de abandono.

Em relação ao ensino fundamental, a distorção idade-série apresentava relação positiva com o abandono em todas as configurações do modelo. A média de alunos por turma apresentava associação positiva, que deixava de ser significativa, por sua vez, com a inclusão do controle por local (urbano em comparação ao rural) e com o ICG. O percentual de docentes com curso superior apresentou coeficientes negativos, até mesmo com a inclusão de todos os controles. $\mathrm{O} \mathrm{R}^{2}$ dos modelos conduzidos apresentava valores ao redor de 0.35 , de modo que as variáveis inclusas nos modelos eram responsáveis por explicar 35\% da variação nas taxas de abandono por escola nos anos finais do ensino fundamental (Apêndice A - Tabela A1). 


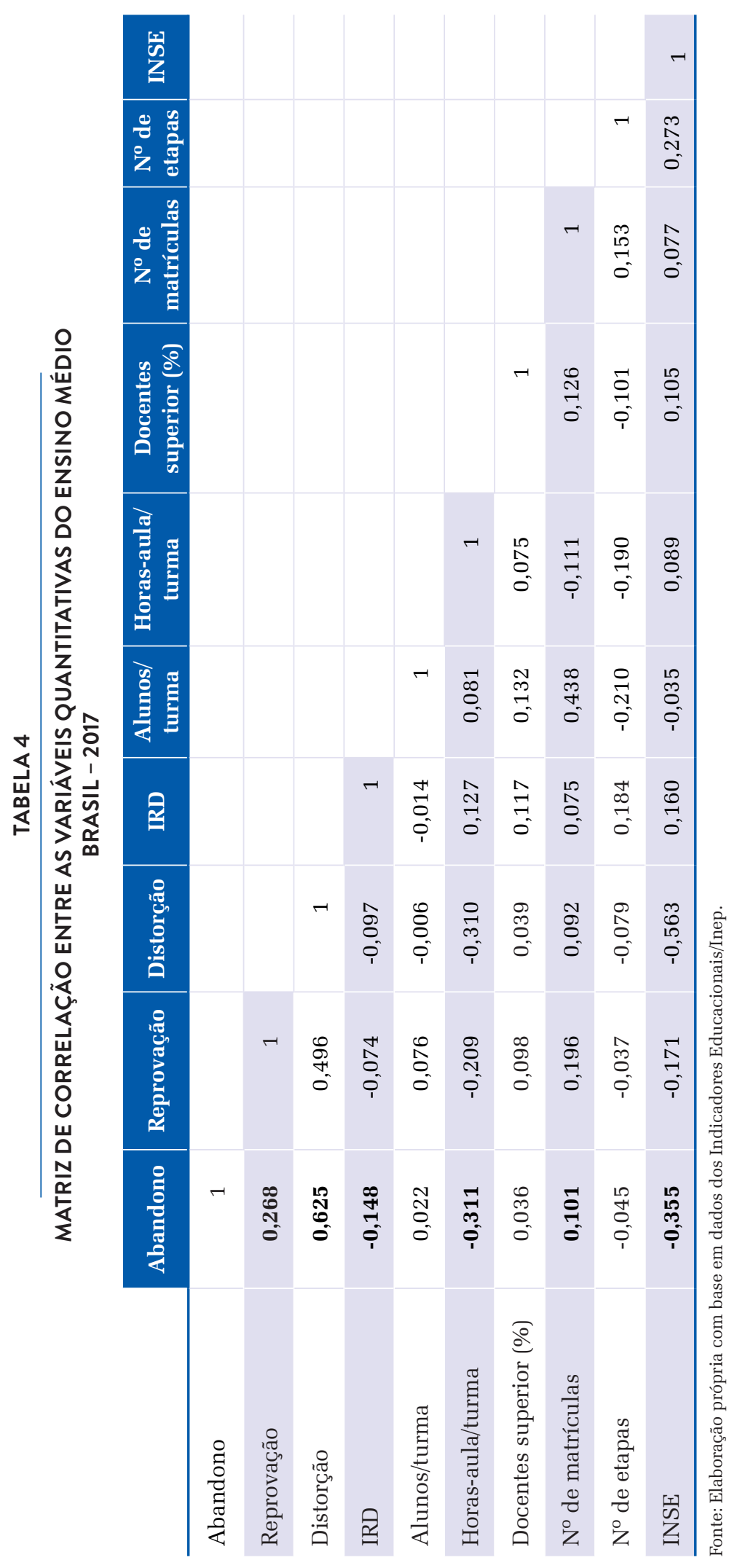


No que se refere ao ensino médio, as variáveis inclusas nos modelos, que partem de uma composição simples e vão incorporando novas independentes, apresentaram um $\mathrm{R}^{2}$ entre 0,39 a 0,41 , o que permite afirmar que eram responsáveis por explicar de $39 \%$ a $41 \%$ da variação total nas taxas de abandono das escolas de ensino médio consideradas na análise.

Em relação à interpretação dos coeficientes, a distorção idade-série apresentou associação positiva com o abandono em todos os modelos utilizados, inclusive com o controle de nível socioeconômico e de localização, tudo o mais constante. Chama atenção a associação negativa entre IRD e abandono, sugerindo que, nessa etapa de ensino, estabelecimentos que contam com a permanência mais contínua do docente apresentam menores taxas de abandono. Situação similar pode ser verificada no que se refere ao número médio de horas-aula por turma, que foi significativo em todos os modelos, indicando que o seu aumento se relacionava, em média, à redução das taxas de abandono, tudo o mais constante, mesmo com a inclusão no modelo de variáveis de controle como a localização da escola e o nível socioeconômico (Apêndice A Tabela A2).

A composição do modelo final para o ensino médio, incluindo as variáveis que compõem o ICG, assim como ele próprio tendo suas categorias transformadas em variáveis dicotômicas para a comparação com o nível de complexidade 1, apresentou valores significativos e coeficientes positivos na comparação entre os níveis mais elevados de complexidade. Como exemplo, escolas com nível de complexidade 6, em comparação ao nível 1, apresentavam, em média, taxas de abandono 3,13 pontos percentuais superiores. Isso ocorria mesmo com a inserção separada de parte das variáveis que integram o ICG, como o número de etapas e matrículas por escola, bem como os controles pelo local e pelo nível socioeconômico (Apêndice A - Tabela A2). 


\section{CONCLUSÕES}

Este estudo identificou alguns fatores intraescolares que se relacionam ao abandono escolar. Utilizou-se de um conjunto de indicadores escolares produzidos pelo Inep para realizar uma análise descritiva das taxas de abandono das escolas brasileiras e dos estabelecimentos de ensino, nos anos de 2014 e 2017, e estabelecer correlações entre eles em 2017. A associação desses indicadores - número de matrículas da escola; número de etapas da escola; média de alunos por turma; média de horas-aula diárias; percentual de docentes com nível superior; índice de regularidade docente; índice complexidade da gestão escolar; indicador de nível socioeconômico das escolas; distorção idade-série e taxas de reprovação - permitiu compor, de modo exploratório, um conjunto de características internas de organização da escola que se desenvolvem sob a gerência dos docentes, do corpo dirigente das instituições ou dos sistemas de ensino e que podem afetar o abandono escolar,

A literatura sobre o abandono, comumente, tem enfatizado a importância de uma variedade de características socioeconômicas, culturais e contextuais, como fatores extraescolares explicativos das desigualdades educacionais. O presente estudo, por sua vez, buscou ressaltar alguns atributos específicos das instituições escolares, que também precisam ser considerados para a afirmação de que as condições nas quais as atividades educacionais são realizadas podem se relacionar às taxas de abandono da escola, porém, é importante registrar que a variável de nível socioeconômico se confirmou como significativa, mesmo com a inclusão de um conjunto de características da escola.

Os estabelecimentos com maior complexidade da gestão são aqueles que convivem com diversas etapas de ensino, um número elevado de estudantes em quantidade maior de turnos, circunstâncias que demandam mais recursos físicos e humanos para o trabalho pedagógico. Quanto mais avançada a idade dos alunos e as etapas oferecidas, gerencia-se um número maior de docentes, mais arranjos para a organização das grades curriculares são necessários e mais desafios são enfrentados para a manutenção do aluno na escola (questões como distorção idade-etapa, conciliação entre trabalho e estudo, questões motivacionais etc.). Isso ficou mais evidente quando se considerou as taxas de abandono no ensino médio, que foram maiores em estabelecimentos mais complexos.

Por outro lado, maior regularidade do corpo docente e maior percentual de professores com ensino superior são características dos estabelecimentos com menores taxas de abandono, especificamente no ensino médio. A alta rotatividade de professores nas escolas pode afetar o estabelecimento de vínculos com a instituição e com os estudantes, pois um docente que permanece pouco tempo na escola tem menos condições de identificar situações específicas dos estudantes e da comunidade 
atendida, de dar continuidade a planejamentos ou de contribuir na resolução de eventuais problemas pelos quais a escola possa estar passando.

A análise priorizou a importância dos chamados fatores "internos" para a compreensão do abandono escolar no ensino fundamental e médio, mas importa destacar que a própria distinção feita entre o que se constitui como externo e interno não é absoluta quando se trata de fenômenos sociais. Os fatores "externos" podem ser (re)produzidos, legitimados no "interior" de instituições escolares e reconhecidos, posteriormente, como pertencentes a esferas quase inatingíveis pela ação, como a "estrutura", o "sistema”. Além disso, aquilo que é produzido internamente na escola em uma determinada etapa da educação básica, como a reprovação e/ou o abandono no ensino fundamental, produz uma distorção idade-série que, posteriormente, no ensino médio - etapa seguinte ao ensino fundamental na qual, geralmente, ocorre uma mudança de instituição -, transforma-se em "fator externo", algo que o indivíduo já porta ao ingressar na nova etapa. Nessa direção, alguns estudos destacam ser importante ter "mais informação acerca dos diferentes atores, de suas instituições escolares e de suas relações intra/extraescolares para entender como os alunos se mostram desinteressados pela escola e não concluem o ensino médio" (Soares et al., 2015, p. 760).

A escola, portanto, compreendida como uma instituição social complexa, possui características organizacionais e estruturais próprias que se articulam às características socioeconômicas dos sujeitos. O abandono, desse modo, se relaciona a um conjunto de fatores que variam de acordo com o contexto social, circunstâncias individuais, familiares. Ao mesmo tempo, fatores relativos à qualidade física e aos processos nos quais a escolarização ocorre também apresentam correlação com o fenômeno e precisam ser melhor explorados conceitual e empiricamente. Assim, compreender a interação entre os componentes "externos" e "internos" pode contribuir para os resultados do abandono, no sentido de sua redução ou reprodução.

Os próximos passos do estudo consistirão em recorrer a análises com dados longitudinais das trajetórias escolares dos estudantes em tipos distintos de oferta de ensino médio (propedêutico ou profissionalizante), de modo a reunir subsídios para refletir acerca do papel da escola e da forma como as características internas de sua organização repercutem nas taxas de abandono escolar. 


\section{REFERÊNCIAS}

ANDRADE, R. J. de; SOARES, J. F. O efeito da escola básica brasileira. Estudos em Avaliação Educacional, São Paulo, v. 19, n. 41, p. 379-406, set./dez. 2008.

BRASIL. Constituição (1988). Emenda Constitucional nº 59, de 11 de novembro de 2009. Acrescenta $\S 3^{\circ}$ ao art. 76 do Ato das Disposições Constitucionais Transitórias para reduzir, anualmente, a partir do exercício de 2009, o percentual da Desvinculação das Receitas da União incidente sobre os recursos destinados à manutenção e desenvolvimento do ensino de que trata o art. 212 da Constituição Federal, dá nova redação aos incisos I e VII do art. 208, de forma a prever a obrigatoriedade do ensino de quatro a dezessete anos e ampliar a abrangência dos programas suplementares para todas as etapas da educação básica, e dá nova redação ao $\S 4^{\circ}$ do art. 211 e ao $\S 3^{\circ}$ do art. 212 e ao caput do art. 214, com a inserção neste dispositivo de inciso VI. Diário Oficial da União, Brasília, DF, 12 nov. 2009. Seção 1, p. 8.

BRASIL. Instituto Nacional de Estudos e Pesquisas Educacionais Anísio Teixeira (Inep). Dicionário de indicadores educacionais: fórmulas de cálculo. Brasília, 2004.

BRASIL. Instituto Nacional de Estudos e Pesquisas Educacionais Anísio Teixeira (Inep). Nota Técnica $n^{\circ}$ 040/2014. Indicador para mensurar a complexidade da gestão nas escolas a partir dos dados do Censo Escolar da Educação Básica. Brasília, 2014. Disponível em: < http://download.inep.gov.br/informacoes_estatisticas/indicadores_ educacionais/2014/escola_complexidade_gestao/nota_tecnica_indicador_escola_ complexidade_gestao.pdf>. Acesso em: 30 maio 2019.

BRASIL. Instituto Nacional de Estudos e Pesquisas Educacionais Anísio Teixeira (Inep). Nota Técnica CGCQTI/DEED/INEP $n^{\circ}$ 11/2015. Indicador de regularidade do docente da Educação Básica. Brasília, 2015. Disponível em: <http://download. inep.gov.br/informacoes_estatisticas/indicadores_educacionais/2014/docente_ regularidade_vinculo/nota_tecnica_indicador_regularidade_2015.pdf $>$. Acesso em: 30 maio 2019.

BRASIL. Instituto Nacional de Estudos e Pesquisas Educacionais Anísio Teixeira (Inep). Nota Técnica: Indicador de Nível Socioeconômico das Escolas de Educação Básica (Inse). Brasília, [2015]. Disponível em: < http://download.inep.gov.br/ informacoes_estatisticas/indicadores_educacionais/2015/nota_tecnica/nota_tecnica_ inep_inse_2015.pdf>. Acesso em: 12 jun. 2019.

BRASIL. Instituto Nacional de Estudos e Pesquisas Educacionais Anísio Teixeira (Inep). Nota Técnica $n^{o}$ 8/2017/CGCQTI/DEED. Estimativas de fluxo escolar a partir 
do acompanhamento longitudinal dos registros de aluno do Censo Escolar do período 2007-2016. Brasília, 2017a. Disponível em: <http://download.inep.gov.br/ informacoes_estatisticas/indicadores_educacionais/2007_2016/nota_tecnica_taxas_ transicao_2007_2016.pdf>. Acesso em: 30 maio 2019.

BRASIL. Instituto Nacional de Estudos e Pesquisas Educacionais Anísio Teixeira (Inep). Indicadores educacionais. Brasília, 2017b. Disponível em: < http://portal.inep. gov.br/web/guest/indicadores-educacionais >. Acesso em: 12 jun. 2019.

BRASIL. Instituto Nacional de Estudos e Pesquisas Educacionais Anísio Teixeira (Inep). Indicadores educacionais: taxas de rendimento: 2007-2017. Brasília, 2017c. Disponível em: <http://portal.inep.gov.br/web/guest/indicadores-educacionais > . Acesso em: 12 jun. 2019.

BRASIL. Instituto Nacional de Estudos e Pesquisas Educacionais Anísio Teixeira (Inep). Taxas de rendimento escolar. Brasília, [2018]. Disponível em: <http://download.inep.gov.br/educacao_basica/educacenso/situacao_aluno/ documentos/2018/taxas_de_rendimento_escolar.pdf>. Acesso em: 12 jun. 2019.

BRASIL. Ministério da Educação (MEC). Portaria n 264, de 26 de março de 2007. Institui o Dia Nacional do Censo Escolar da Educação Básica. Diário Oficial da União, Brasília, DF, n. 59, 27 mar. 2007. Seção 1, p. 100.

BROOKE, N.; SOARES, J. F. (Org.). Pesquisa em eficácia escolar: origem e trajetórias. Belo Horizonte: Editora UFMG, 2008.

DE WITTE, K. et al. A critical review of the literature on school dropout. Educational Research Review, [S.l.], v. 10, p. 13-28, Apr. 2013.

INSPER. Políticas públicas para redução do abandono e evasão escolar de jovens. 2017. Disponível em: <https://www.insper.edu.br/wp-content/uploads/2018/09/ Poli\%CC\%81ticas-pu\%CC\%81blicas-para-a-reduc\%CC\%A7a\%CC\%83o-doabandono-e-evasa\%CC\%83o-escolar-de-jovens.pdf>. Acesso em: 28 maio 2019.

HAIR, J. F. et al. Análise Multivariada de Dados. 6. ed. Porto Alegre: Bookman, 2009.

HUNT, F. Dropping out from school: a cross-country review of literature. Falmer, Brighton: CREATE/University of Sussex, 2008. (CREATE Pathways to Access, n. 16).

INSTITUTO BRASILEIRO DE GEOGRAFIA E ESTATÍSTICA (IBGE). Pesquisa Nacional por Amostra de Domicílios (Pnad Contínua): microdados 2012-2018. Disponível em: <https://www.ibge.gov.br/estatisticas/sociais/trabalho/17270-pnadcontinua.html?=\&t=microdados $>$. Acesso em: 4 jun. 2019. 
KLEIN, R. Produção e utilização de indicadores educacionais: metodologia de cálculo de indicadores do fluxo escolar da educação básica. Revista Brasileira de Estudos Pedagógicos, Brasília, v. 84, n. 206-208, p. 107-157, jan./dez. 2003. Seção: Estatística.

NERI, M. C. (Coord.). O tempo de permanência na escola e as motivações dos sem-escola. Rio de Janeiro: FGV/IBRE; CPS, 2009.

REDDY, A. N.; SINHA, S. School Dropouts or Pushouts? Overcoming Barriers for the Right to Education. Falmer, Brighton: CREATE/University of Sussex, 2010. (CREATE Pathways to Access, n. 40).

SARAIVA, A. M. A. Abandono escolar. In: OLIVEIRA, D. A.; DUARTE, A. M. C.; VIEIRA, L. M. F. Dicionário: trabalho, profissão e condição docente. Belo Horizonte: Faculdade de Educação/UFMG, 2010.

SILVA FILHO, R. B.; ARAÚJO, R. M. de L. Evasão e abandono escolar na educação básica no Brasil: fatores causas e possíveis consequências. Revista Por Escrito, Porto Alegre, v. 8, n. 1, p. 35-48, jan./jun. 2017.

SIMÕES, A. A. As metas de universalização da educação básica no Plano Nacional de Educação: o desafio do acesso e a evasão dos jovens de famílias de baixa renda no Brasil. Brasília: Inep, 2016. (PNE em Movimento, 4).

SOARES, T. M. et al. Fatores associados ao abandono escolar no ensino médio público de Minas Gerais. Educação e Pesquisa, São Paulo, v. 41, n. 3, p. 757-772, jul./set. 2015.

STRATTON, L. S.; O‘TOOLE, D. M.; WETZEL, J. N. A Multinomial Logit Model of College Stopout and Dropout Behavior. Bonn: The Institute for the Study of Labor, 2005. (IZA Discussion Paper Series, n. 1634).

WOOLDRIDGE, J. M. Introdução à econometria: uma abordagem moderna. Tradução de José Antônio Ferreira da 4. ed. norte-americana. 2. ed. São Paulo: Cengage Learning, 2016. 


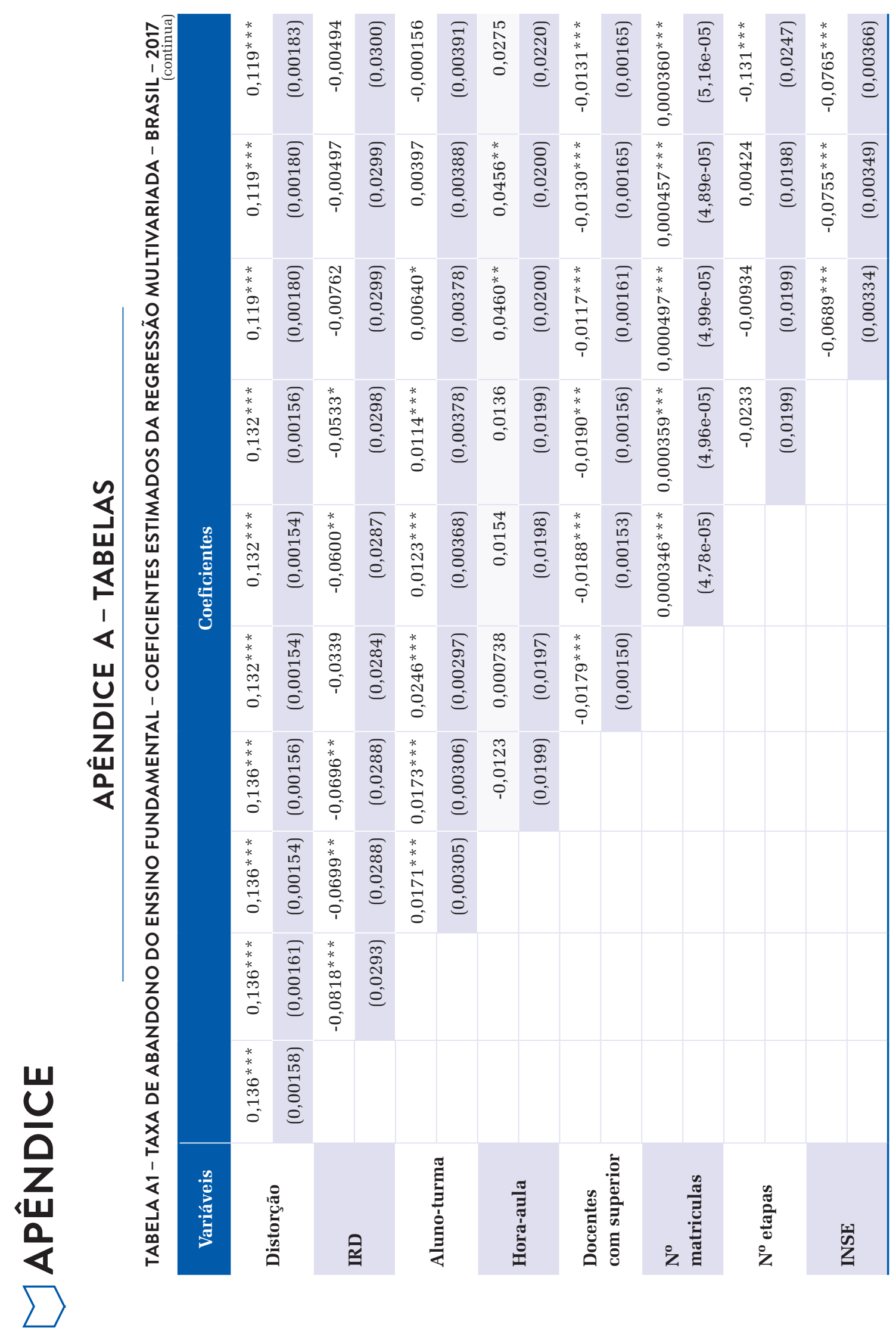




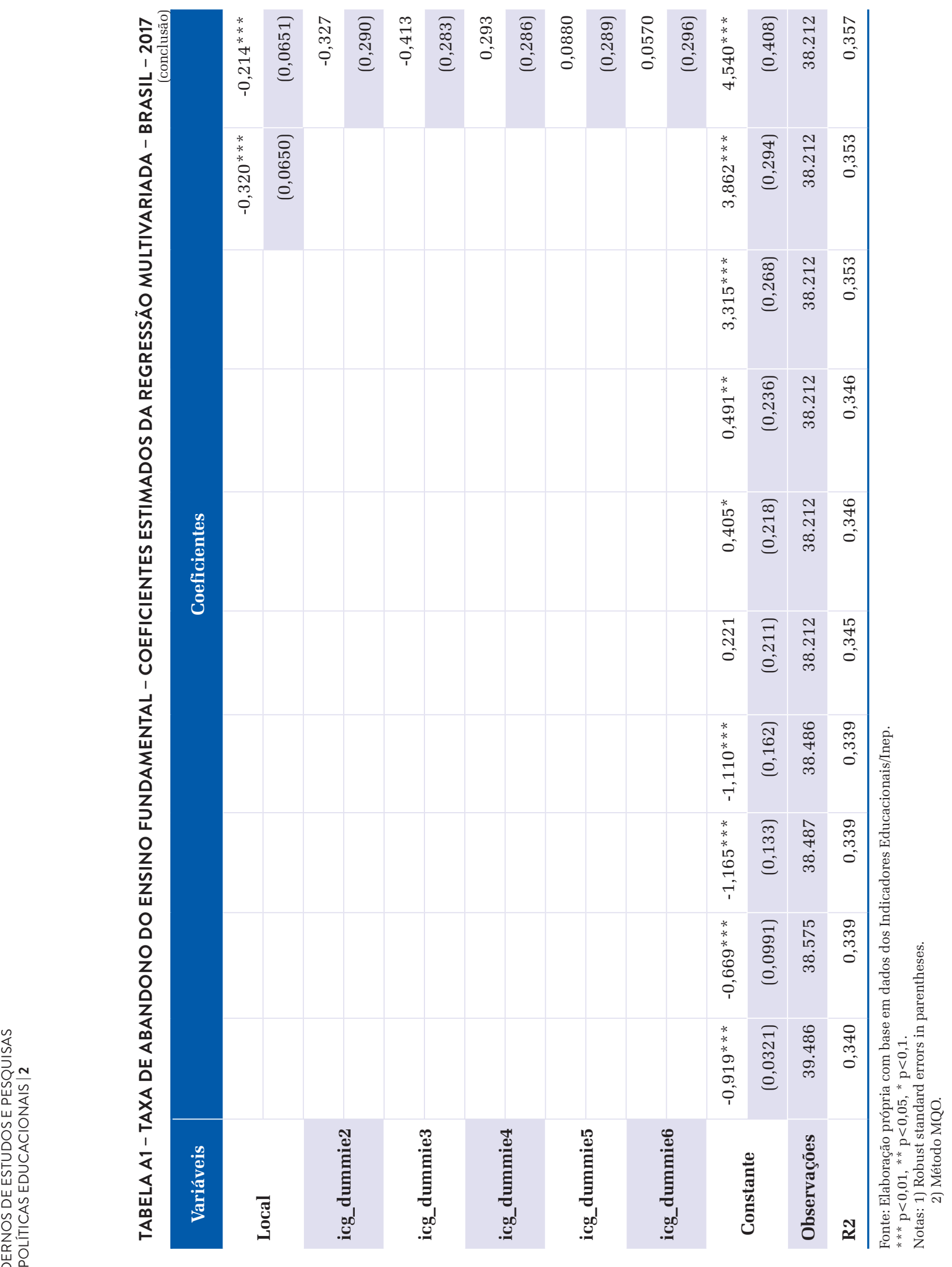




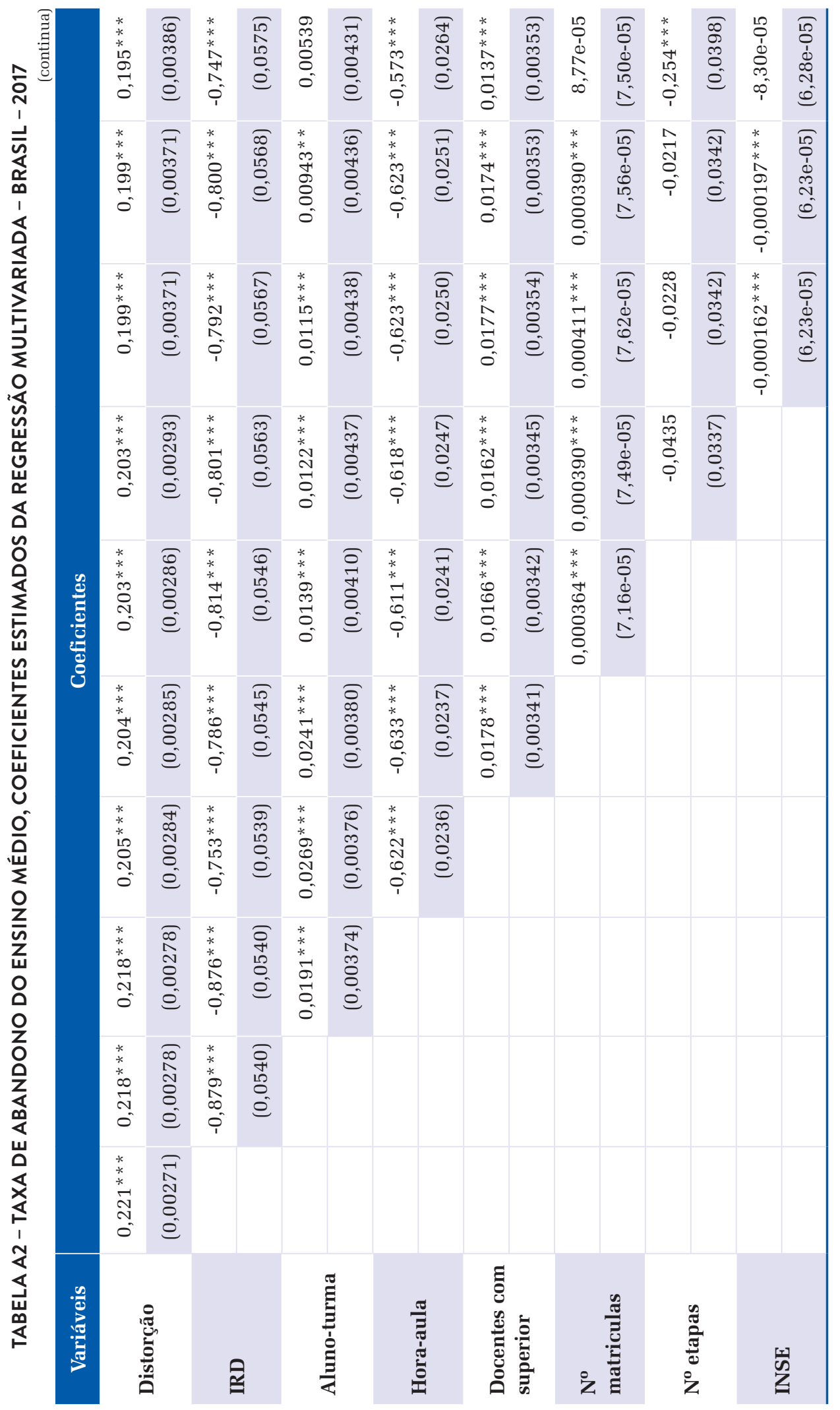




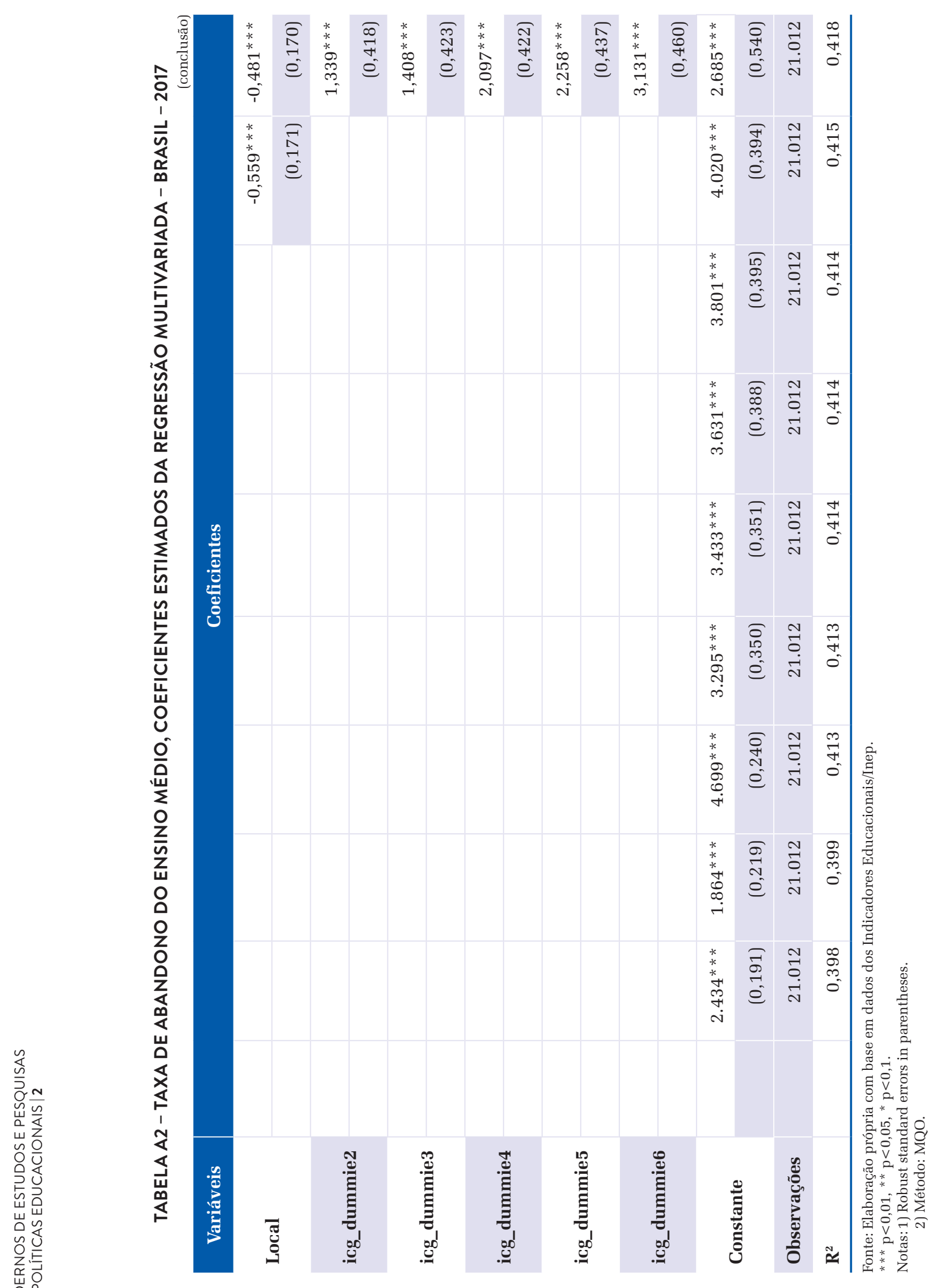

